\title{
Continuous GPS Observations of Postseismic Deformation Following the 16 October 1999 Hector Mine, California, Earthquake ( $\left.M_{\mathrm{w}} 7.1\right)$
}

\author{
by K. W. Hudnut, N. E. King, J. E. Galetzka, K. F. Stark, J. A. Behr, A. Aspiotes, \\ S. van Wyk, R. Moffitt, S. Dockter, and F. Wyatt
}

\begin{abstract}
Rapid field deployment of a new type of continuously operating Global Positioning System (GPS) network and data from Southern California Integrated GPS Network (SCIGN) stations that had recently begun operating in the area allow unique observations of the postseismic deformation associated with the 1999 Hector Mine earthquake. Innovative solutions in fieldcraft, devised for the 11 new GPS stations, provide high-quality observations with 1-year time histories on stable monuments at remote sites. We report on our results from processing the postseismic GPS data available from these sites, as well as 8 other SCIGN stations within $80 \mathrm{~km}$ of the event (a total of 19 sites). From these data, we analyze the temporal character and spatial pattern of the postseismic transients. Data from some sites display statistically significant time variation in their velocities. Although this is less certain, the spatial pattern of change in the postseismic velocity field also appears to have changed. The pattern now is similar to the pre-Landers (pre-1992) secular field, but laterally shifted and locally at twice the rate. We speculate that a $30 \mathrm{~km} \times 50 \mathrm{~km}$ portion of crust (near Twentynine Palms), which was moving at nearly the North American plate rate (to within $3.5 \mathrm{~mm} / \mathrm{yr}$ of that rate) prior to the 1992 Landers sequence, now is moving along with the crust to the west of it, as though it has been entrained in flow along with the Pacific Plate as a result of the Landers and Hector Mine earthquake sequence. The inboard axis of right-lateral shear deformation (at lower crustal to upper mantle depth) may have jumped $30 \mathrm{~km}$ farther into the continental crust at this fault junction that comprises the southern end of the eastern California shear zone.
\end{abstract}

\section{Introduction}

The precise measurement of postseismic deformation is an essential observational contribution of geodesy toward an improved understanding of fault-zone mechanics, as well as the slow processes of crustal and subcrustal relaxation and recovery that occur in the aftermath of a large earthquake. It has long been recognized that large earthquakes generate lasting postseismic deformation signals (e.g., Thatcher, 1983), with temporal decay rates extending to decades (e.g., Kenner and Segall, 2000). Interpretations of these transient signals recently have provided new insights into interseismic fault-loading phenomena (e.g., Gilbert et al., 1994), postseismic phenomena explained by both poroelastic (Peltzer et al., 1996, 1998) and viscoelastic (Deng et al., 1998) source mechanisms, and the behavior and rheology of the lower crust and upper mantle (e.g., Pollitz et al., 2000).

Following the 1992 Landers earthquake sequence (e.g., Sieh et al., 1993), numerous studies investigated various aspects and observations of postseismic transient deformation associated with that sequence (e.g., Shen et al., 1994; Wyatt et al., 1994; Peltzer et al., 1996, 1998; Deng et al., 1998; Pollitz et al., 2000). These studies provided us with insight about the postseismic deformation we might expect as a result of other earthquakes in the region. We recognized, soon after the $1999 M_{\mathrm{w}} 7.1$ Hector Mine earthquake, that displacements along the surface ruptures were significant $(>5 \mathrm{~m})$, and that the static displacement field was substantial (e.g., Hurst et al., 2000; Scientists of the USGS, et al., 2000; Treiman et al., 2002). Further coseismic source modeling is providing details of the Hector Mine event's slip distribution, through integrative studies using various types of coseismic data (e.g., Dreger and Kaverina, 2000; Fialko et al., 2001; Ji et al., 2002a, b; Kaverina et al., 2002). We realized, on the basis of the Landers postseismic studies, that we could reasonably expect to record transient displacement signals associated with the Hector Mine earthquake that would be measurable with continuous GPS, with time constants ranging from a few weeks to a few months, yet likely having amplitudes smaller than those observed following the much 
larger moment release of the Landers sequence. As shown in Figure 1, the SCIGN station stations did indeed record small postseismic motions.

With various new types of high-quality data, it should be possible to establish models relating coseismic source properties and the resulting observed postseismic deformation. With only 1 year of postseismic data so far, however, we have yet to fully develop such models. Special deployments of continuous GPS stations, such as the Hector Mine deployment, certainly can help to address scientific questions about many aspects of postseismic phenomena. We hope that this documentation of the methods developed and data acquired will serve to improve future experiments.

\section{Description of the Deployment}

At the time of the Hector Mine earthquake, on 16 October 1999, SCIGN had recently built or brought online seven new stations within $80 \mathrm{~km}$ of the earthquake (BBRY, WOMT, BSRY, OAES, CTMS, LDES, and GMRC; see Fig. 1). Data from these and other long-running SCIGN sites (such as WIDC in Fig. 1) exhibit both coseismic offsets and postseismic deformation in the months following the event (e.g., Hurst et al., 2000; Scientists of the USGS et al., 2000). All of the data from these SCIGN sites have been made openly available immediately after download, in accord with SCIGN's open data policy. In addition to the fully operational stations, several SCIGN sites in this area had been built but not yet had telemetry established. SCIGN personnel and contractors rapidly completed telemetry where possible, and began a regular schedule of manual downloads where it was not.
Once logistical arrangements were finalized with the Marine Corps Air Ground Combat Center (MCAGCC), at Twentynine Palms Marine Corps Base, where the Hector Mine rupture occurred, SCIGN began installing new stations near the rupture, both on and off the base. Within a few days we had established three new sites (OPRD, OPCX, and LDSW; see Fig. 1), using solar power and radio telemetry (see Fig. 2 and 3). These three sites were constructed with metal piers that we had fabricated earlier, in anticipation of rapid deployments. The piers are mounted with a flange bolted to the surface of a solid, flat surface such as a concrete slab (Fig. 4). In the uneven ground and fractured rock encountered in the field, we excavated pits and drove in rebar ( $1 \mathrm{~m}$ at most), to set the lower portion of the pier into the ground, and set the flange into a concrete mass instead of bolting it in place. Concern about stability of these piers led us to develop a more stable GPS antenna monument, under the constraints imposed by reasonably priced helicopter transport on the weight and size of hardware, tools, and equipment needed for station installation. We describe this new method in the following section.

During late October and early November 1999, reconnaissance and permitting of sites outside and within MCAGCC were all performed. There were numerous considerations made when designing the Hector Mine continuously operating GPS array. We wanted to cover the near- and intermediate-field area, placing stations in roughly quadrilateral arrangements at increasing distances from the fault. We wished to cover all four quadrants around the rupture and to complement the spatial coverage that we knew was being obtained by our colleagues using survey-mode GPS. Furthermore, we had to consider practical constraints and

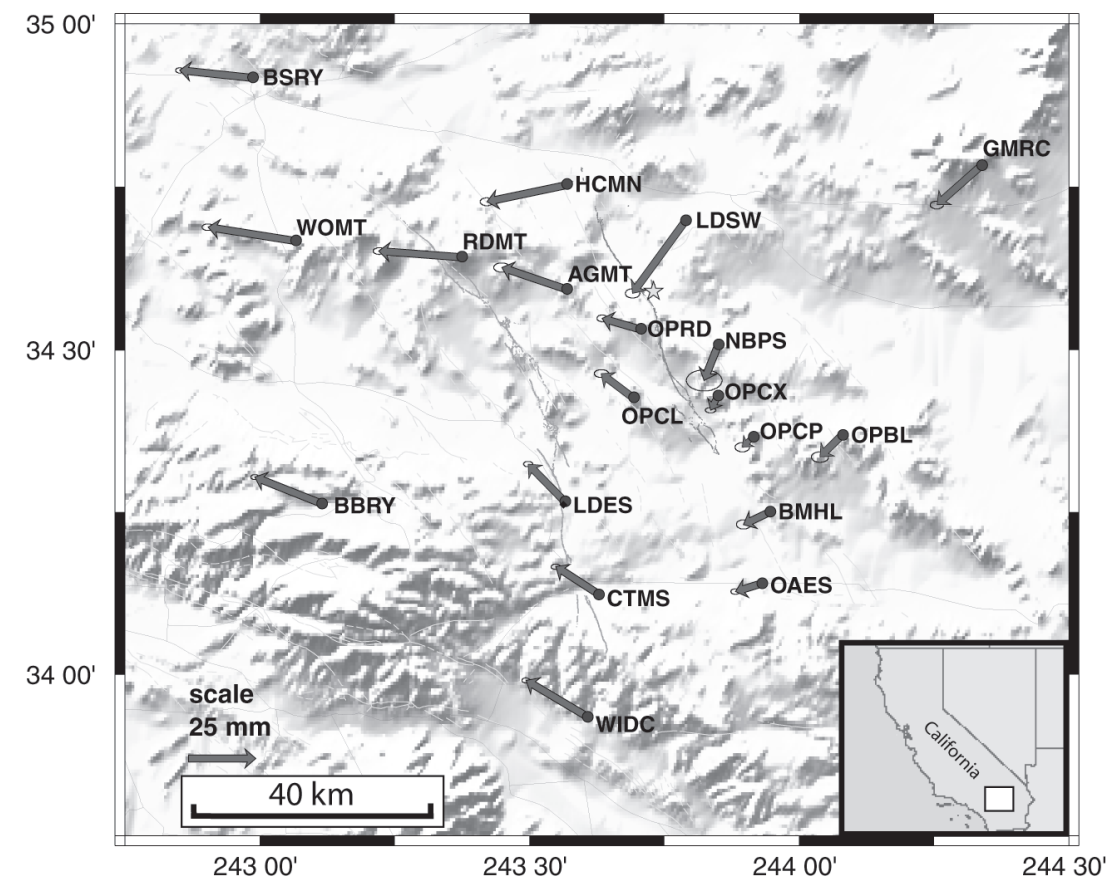

Figure 1. Map of postseismic displacement vectors at 19 Southern California Integrated GPS Network (SCIGN) sites, estimated as a best linear fit from one year's data since the Hector Mine earthquake (see Table 3). Vectors have not yet been corrected for the secular velocity, Landers postseismic deformation, or reference frame shift (see Table 5 and Fig. 10). This map also shows the 1992 Landers sequence and 1999 Hector Mine surface ruptures; the Hector Mine epicenter is indicated by a star. 


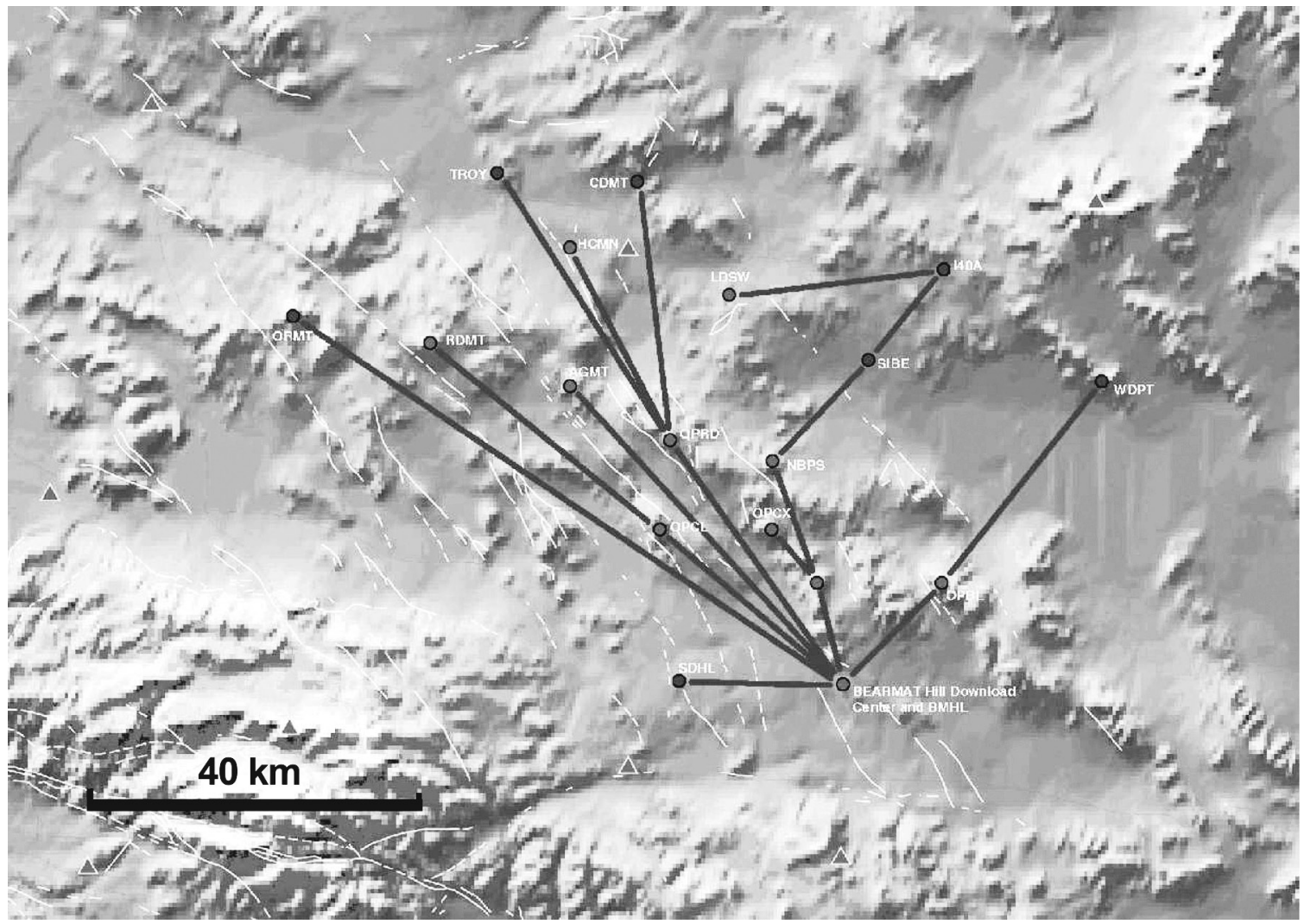

Figure 2. Map of the Twentynine Palms SCIGN subnetwork telemetry shots. Spread spectrum radio signals are transmitted, repeated, and received through a network controlled by the SCIGN SHARC/EGADS software. The system is run by a single computer located on the U.S. Marine Corps Twentynine Palms base at BEARMAT Hill.

field logistics. In response to all of these considerations, and especially the last, we chose mountaintop sites (many at observation posts, or OPs). Within MCAGCC, we selected sites within pre-existing no-fire areas. The sites chosen offered the following advantages:

- Good spatial distribution of sites around the fault rupture

- Line-of-site visibility for radio telemetry

- Better GPS sky view

- Greater likelihood of solid bedrock outcrops for stable monuments

- Increased security

Knowing, furthermore, that the 1992 Landers postseismic deformation signals tended to have temporal decay rates on the order of weeks to several months, we realized that we had to act quickly. We were limited, however, to working during windows of opportunity at MCAGCC that coincided with periods of inactivity on the base. New procedures, designs (Fig. 5), and special tools were tested in the field between late October and early November at the Rodman Mountain and Hector Mine sites (both accessible by vehicle and outside MCAGCC). Our experiences at these first two installations prepared us for the next helicoptersupported installations in mid-November. At that time, we were able to complete the installation of stations at Noble Pass and OP Creole, and to drill the site at Argos Mountain. In mid-December we installed two vehicle-accessible sites on MCAGCC (at OP Crampton and BEARMAT Hill), and in one additional day with helicopter support we completed the Argos Mountain site, troubleshot several sites, and installed the OP Bullion site. Photos of these sites (Fig. 6) show the completed monuments and equipment enclosures. We also set up our computer and radio system, establishing the GPS data acquisition hub (Figs. 2 and 3). By January, the data from all 11 of these new sites, and from two survey-mode GPS sites (Troy and Siberia), were flowing into the SCIGN data stream.

In all, 11 fully operational stations were deployed within about 3 weeks of total time in the field (spread out over 2.5 months time), by crews of between two and four people. By the end of this field deployment, we had refined our methods such that, in a single day, a well-trained crew of three could fully install one site using less than 3 hours of helicopter flying time, as long as the site was within about $50 \mathrm{~km}$ of the helipad used for staging. We have since used these same methods of field deployment to establish new SCIGN stations on several of the Channel Islands, and we have trained our contractor to install this type of station for SCIGN as well. 


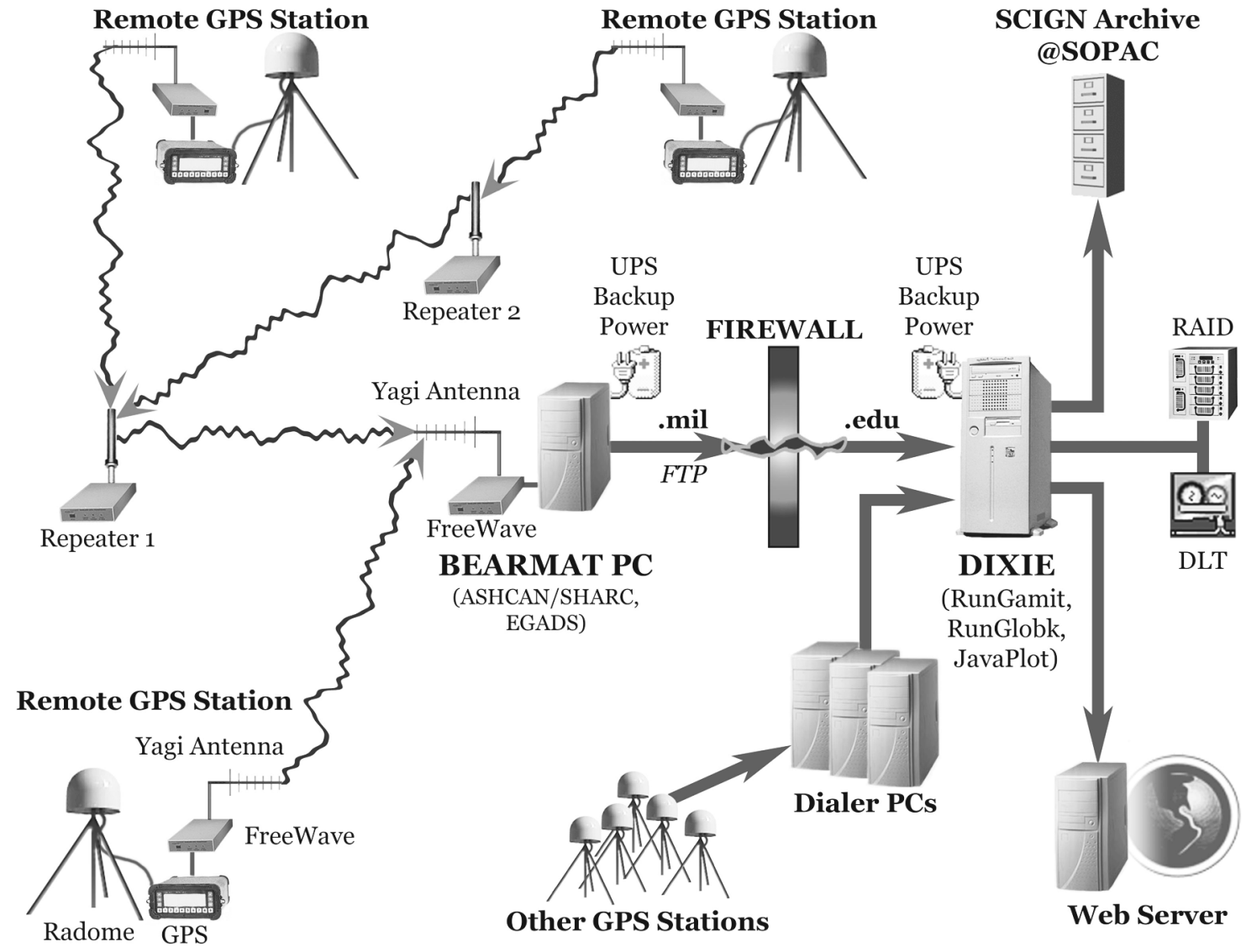

Figure 3. Diagram of the system developed to telemeter, process, store, and distribute the GPS data, as well as process the data and display results rapidly on the World Wide Web.

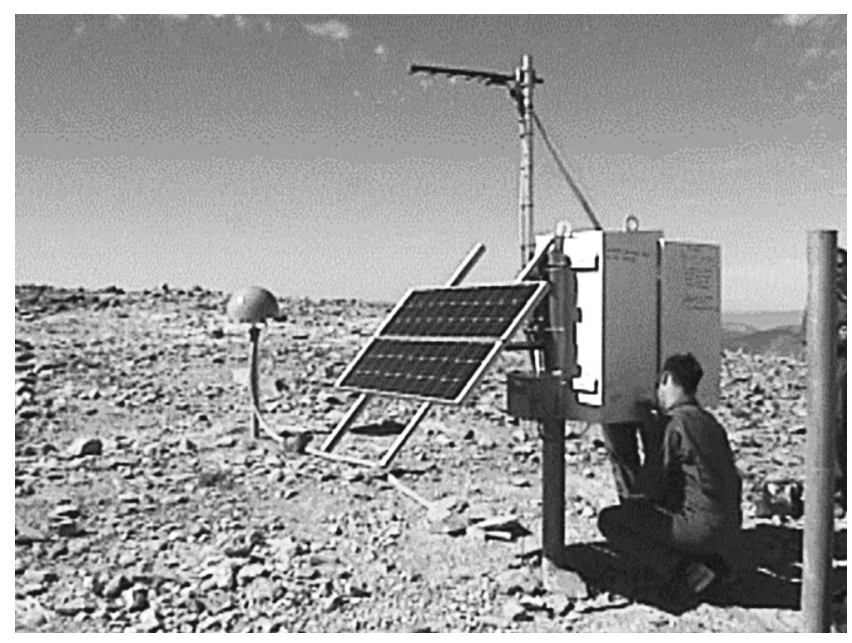

Figure 4. SCIGN station OP Round, installed within the first week after the Hector Mine earthquake. The pier monument type was later abandoned, and we began using a new drilled-braced monument style. Other aspects of the installation work also were refined after these first few stations were emplaced.
We expect that, for at least 10 of the remaining 25 SCIGN stations still to be built, we will apply these methods.

New station-installation efforts were coordinated with survey-mode GPS measurements made by the Southern California Earthquake Center (SCEC) and the U.S. Geological Survey. After our work through the end of 1999, we felt that further SCIGN deployment of new sites would be less likely to capture the relatively rapid postseismic signals of interest that best could be measured with continuous GPS. Other practical factors, such as limits to funding and our other high-priority tasks on the rest of the SCIGN deployment (e.g., handling the end-of-year 2000 or Y2K problem and getting the rest of the network built) influenced our decision.

\section{Methods and Data}

We describe the innovative aspects of the field deployment that we hope will prove useful to other investigators elsewhere, and then describe the data processing methods used in this study.

\section{Monumentation}

Our aim in developing monumentation for this kind of rapid deployment was to get the best-quality monuments 
(a)

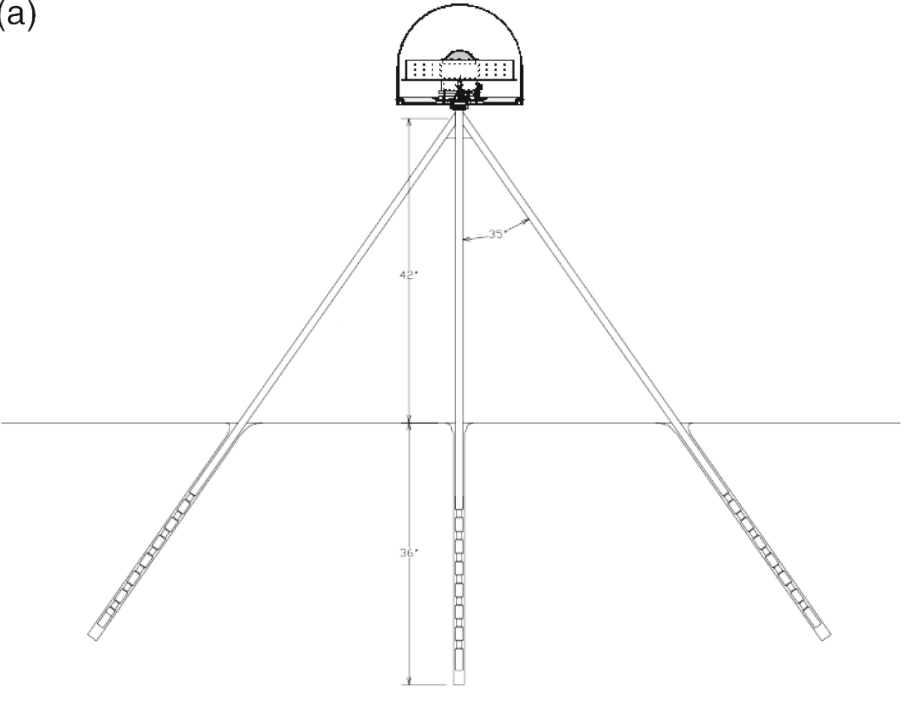

(b)

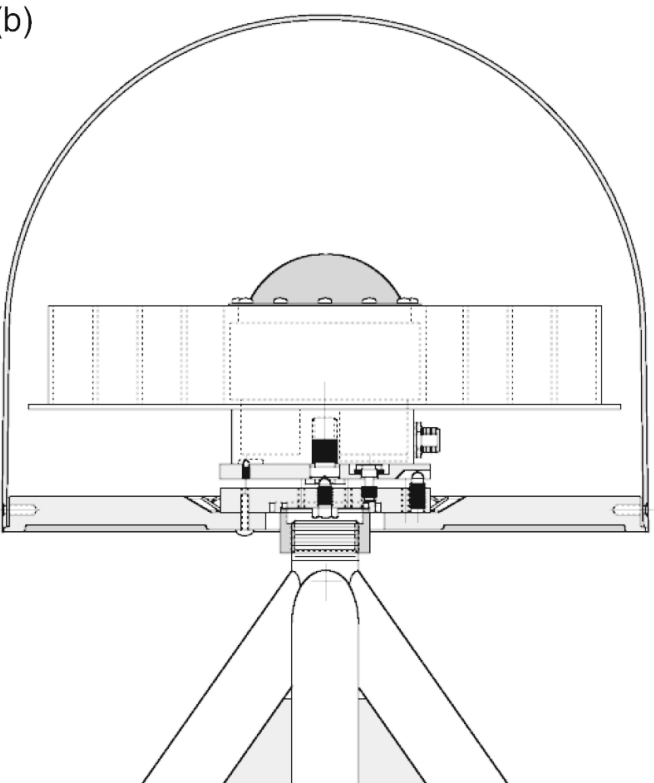

Figure 5. (a) Monument assembly. The vertical leg and three slanted holes are drilled in precise alignment so as to join at a point aboveground. The steel legs are epoxy glued into these holes, and then welded together with gussets. The SCIGN adaptor is welded in place, and then the antenna and SCIGN radome are attached to complete the assembly. (b) The SCIGN monument, adaptor, and radome are designed especially for use with Dorne-Margolin choke ring antennas. These antennas have become the worldwide standard for precise GPS geodetic research purposes (in the International GPS Service [IGS] and many regional networks). The components are designed to provide all necessary functions. The antenna can be readily adjusted to level, oriented to north, and then secured against tampering. Once enclosed, the antenna is protected from the elements, yet the GPS signal distortion due to the radome is expected to cause less than 0.1-mm change in apparent phase-center position.

possible, subject to the logistical constraints of helicopter installation and given the availability of bedrock outcrops at our planned sites. SCIGN's standard monumentation procedure is to deeply anchor the monument wherever possible, using either a drill rig to achieve 10-m depths, or a jackhammer to drill up to $3 \mathrm{~m}$ deep. The latter method has been used previously at SCIGN stations Holcomb Ridge, San Clemente Island, and Wide Canyon with the desired result of stable and secure monuments; however, even a jackhammer (with compressor) cannot be carried in any reasonably available helicopter. We experimented with coring drills and gaspowered rotary hammer drills, and eventually found that generator-powered rotary hammers work best. A 14-amp rotary hammer drill that we selected performed well in a variety of rock types, though not in rock that is poorly consolidated, badly fractured, or at sites with large boulders in a loose matrix.

The final monument design is a braced tripod, with each leg expoxy-glued into a hole about $1 \mathrm{~m}$ deep (Fig. 5a). Installation involves the following steps: drill the vertical hole, determine the piercing points for the other legs, drill the holes for them, epoxy in all the legs, weld them together, and weld an adaptor-mount onto the vertical leg at the intersection point. SCIGN calls this type of monument an SCIGN short-braced rod monument; we are making a description of it available to the GPS community, as we have for our other designs (http://www.scign.org/arch/sdb_ monument.htm).

Of the 11 sites installed in response to the Hector Mine earthquake, 8 used the SCIGN short-braced rod monument. Six of these 11 sites required helicopter access; the other 5 are accessed by four-wheel-drive vehicle. The average cost of the standard SCIGN site to date has been about $\$ 20,000$ (not including GPS hardware, site selection, site permitting, or site evaluation reports). The comparable cost for each of these post-Hector Mine installations was approximately half of this, partly reflecting the lower cost for monumentation but also differences between working in a desert versus an urban environment.

There is a crucial trade-off implicit in the use of this monument design. This design of monument may sacrifice the very high stability we strive for in our drilled-braced installations in the rest of SCIGN. While installation of the new monument type in competent bedrock may alleviate concerns about instability to some degree, its use does strictly require competent bedrock. For this reason, it could not have been applied to most of the area being studied by SCIGN. Given the need for promptness in making post- 

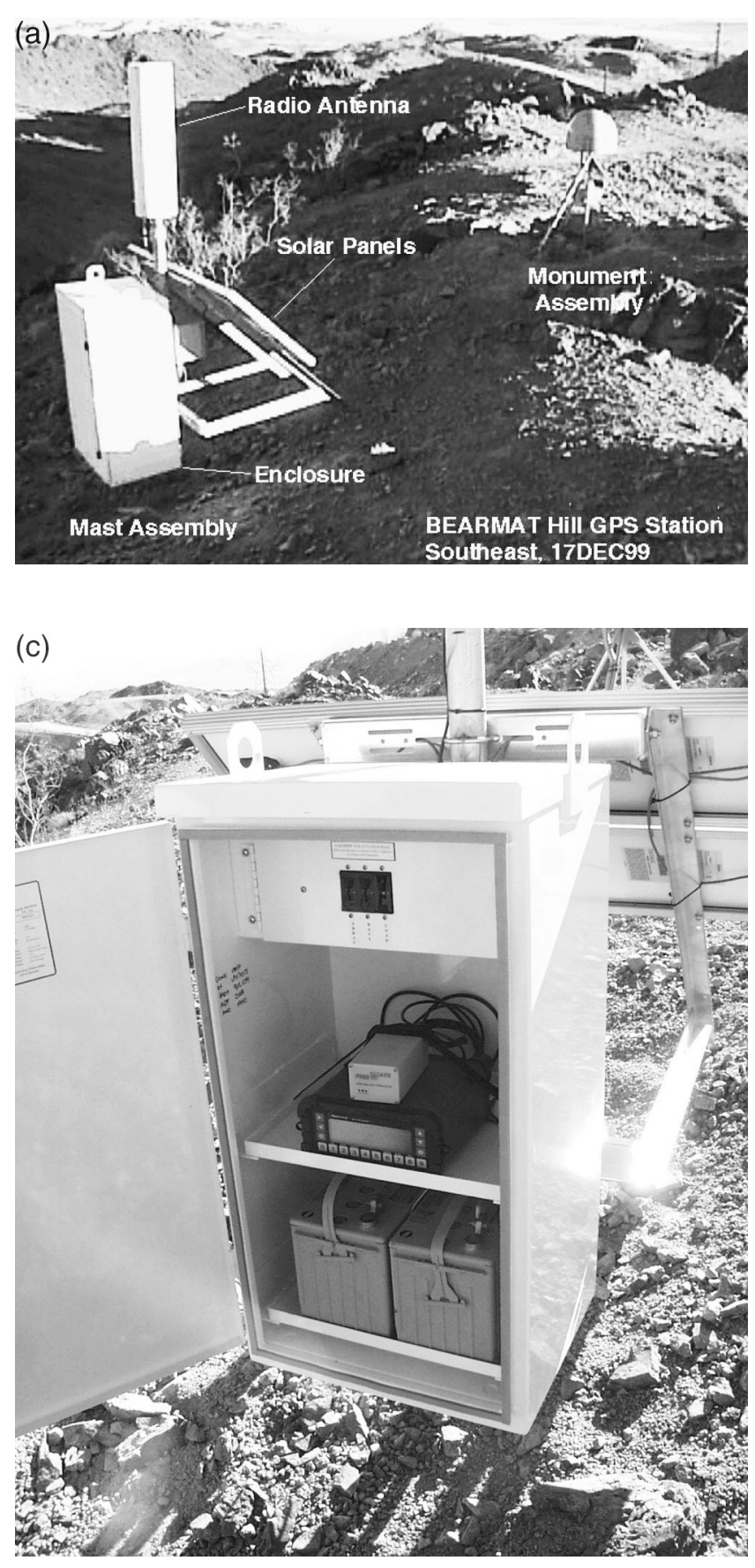

earthquake measurements, the logistical constraints in the epicentral region, and the much higher rates associated with postseismic signals, we feel that we have made a reasonable trade-off in deploying this design.

This method, we have found, is both more acceptable and less intimidating to potential site hosts. They are quicker to approve such low-impact installations than those requiring full-sized drill rigs. The environmental impact of such installations is much reduced, compared to regular SCIGN sites installed by a drill rig. For these reasons, we feel that this style of site installation may have broad application

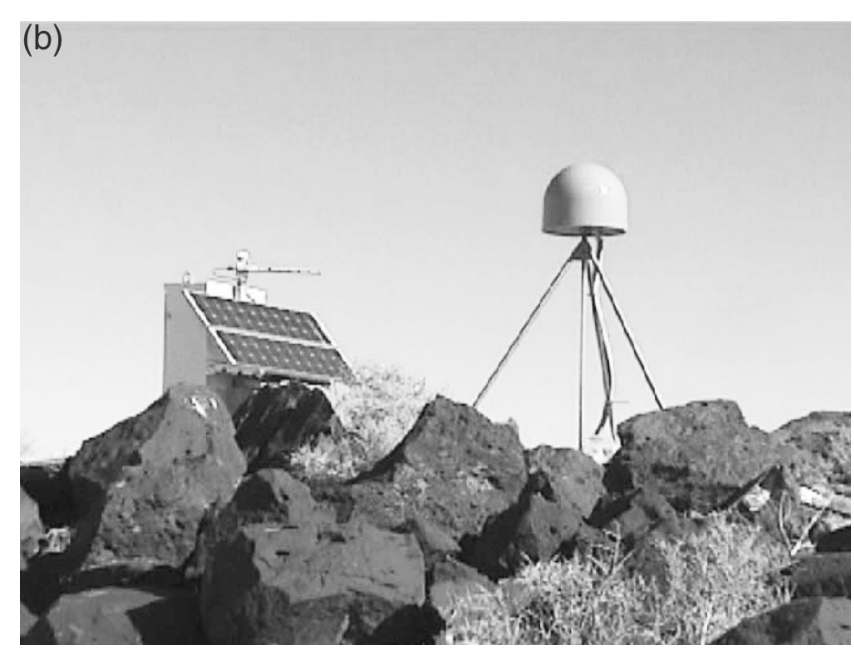

Figure 6. (a) A new-style SCIGN station, installed 2 months after the Hector Mine earthquake, using the new method of monumentation. (b) Completed monument assembly at Argos Mountain. (c) Contents of the equipment enclosure at BEARMAT Hill GPS station. The solar panels and controller charge the two large-capacity batteries, which power both the GPS receiver and the spread spectrum radio used to telemeter the data.

within the proposed Plate Boundary Observatory and elsewhere. We hope that others who are constructing networks of continuously operating GPS stations will consider adopting these methods.

\section{SCIGN Adaptor and Radome}

As part of SCIGN's original goal to ensure optimal network consistency, SCIGN investigators identified two areas in continuous GPS station and network design that needed improvement: the antenna adaptor and antenna radome. Early during the SCIGN development process, committees 
were formed to identify weaknesses and to recommend improved designs. As a result, SCIGN developed more precise adaptors and radomes (Fig. 5b), which have been made available to the greater GPS community. We report briefly on these here, because they were used during the Hector Mine post-earthquake GPS deployment, but we have not previously published any description of these items. Detailed information about the SCIGN adaptor and radome design, including final technical drawings of all parts, are available on the Web at http://pasadena.wr.usgs.gov/scign/group/ domel.

The new adaptor design allows SCIGN to replace antennas on monuments, with high precision. This means that if an antenna change is necessary over the lifetime of the project, there will be no break in the station position time-series that might weaken our velocity estimates (e.g., H. Johnson, SCIGN Analysis Committee Report 1, and personal comm., 1999; J. Langbein, SCIGN Analysis Committee Report 2, and personal comm., 2000). The SCIGN adaptor is designed to allow the antenna to be securely attached to the monument using a kinematic mount; hence, remounting of antennas is precisely repeatable. Antenna heights are constant, and the vertical and horizontal datum points are the same. Pressure points are rounded to minimize metal fatigue. Furthermore, the design is highly resistant to tampering, and when used with the SCIGN tall radome can reduce site vandalism, while still obtaining the best possible GPS signals from our equipment.

We researched a variety of antenna dome-enclosure materials and design considerations to make a precisely calibrated radome that would protect the antenna, affect the GPS signal as little as possible, and be easy to replace. The new design used a hemispherical shape, centered on the physical center of the antenna element. It also featured a uniform wall thickness and density, produced to tight tolerances using the highly repeatable manufacturing process called injection molding. To fill such a large mold ( $\sim 400 \mathrm{~mm}$ diameter) with such thin walls $(\sim 3 \mathrm{~mm})$, this method required a less viscous plastic resin than, say, a pure polycarbonate. The resins we researched are more fragile, because they have shorter polymer chains than does polycarbonate; however, these resins are also less susceptible to degradation due to exposure to sunlight. For additional protection against weather, we selected appropriate pigments and additives as well. Physical design considerations included optimizing the gaps between parts (accounting for tolerances, and to allow a wide temperature range) and also the attachment fixtures and hardware. We worked out the manufacturing steps required (drilling, installation of ultrasonic inserts, and pad printing) for fixtures after the parts had been molded. The design of the new radome was completed in May 1998; the molds were constructed in the summer of 1998; and sample domes were examined and tested by SCIGN in December 1998 and were found to be acceptable. SCIGN tested the domes and made all data from these tests available to the community for further evaluation.

\section{Telemetry and Data Download System}

We established an entirely wireless telemetry network, arranged in a modified radial topology, with shots as long as $30 \mathrm{~km}$ (Figs. 2 and 3). We use Freewave DGR-115 spread-spectrum radios that operate in the frequency band of 902 to $928 \mathrm{MHz}$. These are operated at the nominal 1watt transmission power level. Antennas used are all horizontally polarized, and we use both 10-dB Yagi antennas and 6-dB omnidirectional antennas. For lines that do not use repeater radios, we obtain up to 115 kilobytes/sec effective throughput rates; for lines hitting one or more repeaters, the rate is about half that. All GPS receivers are remotely configured, controlled, and downloaded using this radio network. Currently, we use this to download each day's data file from each GPS station sequentially. A computer at the unmanned BEARMAT Hill download center automatically retrieves all of the data via the network and then forwards all data files by file transfer protocol (ftp) through the MCAGCC firewall back to the USGS-SCIGN computers in Pasadena. The computer at BEARMAT Hill initially ran two software packages developed using SCIGN support, ASHCAN and EGADS (http://egads.sourceforge.net), both of which ran on a personal computer (PC) under the Windows NT4 operating system. This was later replaced with a PC running under the Linux operating system and a replacement for ASHCAN called SHARC. The new SHARC program (http://sharc.sourceforge.net/) also runs with EGADS and the UNAVCO-developed TEQC program (http://www.unavco. ucar.edu/software/teqc/). Once the data have been acquired, transferred, and converted into RINEX format, they are ready on our SCIGN-USGS system for automated processing by GAMIT.

\section{GPS Data and Data Processing}

We present results from the USGS-SCIGN group's precise processing of 19 selected continuously operating SCIGN stations within the epicentral vicinity. These data include SCIGN stations that became operational shortly before the earthquake, as well as the additional SCIGN stations that the USGS-SCIGN group deployed in the days and weeks after the earthquake. All of the data we present here are from after the earthquake; the coseismic displacements measured by SCIGN have already been reported (Hurst et al., 2000; Scientists of the USGS et al., 2000). Our results do not include any data from the extensive survey-mode GPS stations that were resurveyed by several institutions with coordination by the Southern California Earthquake Center (SCEC); those results are presented in Agnew et al. (2002) and Owen et al. (2002).

Within SCIGN, the USGS-SCIGN group is responsible for providing earthquake response information. To do so with the shortest possible latency, while still maintaining reasonable telemetry costs and with our existing computational resources, we process all data from SCIGN once every 24 hours. To produce a daily solution as quickly as possible 
after data retrieval, the USGS-SCIGN group has, for several years, been routinely processing the data using predicted and rapid satellite orbital parameters from the International GPS Service (IGS) (Beutler and Neilan, 1997). Recently, we have improved our earthquake response information system. We perform an initial run using precise predicted orbits (as we have done since 1996, but with ongoing refinements). We now reprocess all available data in three subsequent daily processing runs: one after 4 days using the rapid orbits, another after 14 days using precise orbits, and a final run after 42 days (again using precise orbits). Each run also incorporates more data, since some stations come in late. We now routinely produce results using the final precise IGS orbits, in the same manner that we reprocessed results for this article. Soon we will begin downloading and processing SCIGN data on a subdaily basis, to further improve our earthquake response capabilities. For postseismic deformation monitoring, this will also better enable us to provide information more rapidly in the event of any large aftershocks, especially on the rates of postseismic deformation. Timely information of this type can be very useful to the surveying and engineering communities following large events, in part to help them decide how long to wait before they conduct surveys to repair damage to their geodetic infrastructure.

To make analysis of data from all of the SCIGN stations practical on a daily basis, stations are grouped into several subregions and processed in parallel using GAMIT software (King and Bock, 1999). For this article, we concentrate on the data from SCIGN stations from two such subregions that encompass the earthquake. Four stations from the IGS global network were included in each subregional solution. The positions of these reference stations were tightly constrained to their 1996 International Terrestrial Reference Frame (ITRF96) (Sillard et al., 1998) coordinates. The station positions, variance-covariance matrices, and other parameters from the GAMIT solution were then combined in GLOBK, a Kalman filtering routine described by Herring (1999), to produce estimates of station coordinates in the ITRF96 reference frame. As a final step, the entire southern California solution determined in GLOBK was transformed, rotated, and scaled to fit with a very well known set of 30 SCIGN station coordinates and velocities using GLOBK's GLORG reference frame stabilization module. This step removes regionwide, common-mode biases on the order of 10 to $20 \mathrm{~mm}$ in the SCIGN horizontal station coordinates. We then extracted the time-series of station positions from the GLOBK output files (plotted in Fig. 7). We performed a least squares linear fit individually to each component (NEU) of each GPS station's time-series. The best-fitting velocities are given in Table 3 and shown in Figure 1. As can be seen in Figure 7, some of the data are not adequately represented by these linear fits. The parameters estimated for the three time intervals we selected for piecewise linear fits are given in Table 4 and in Figures 8 and 9; exponential functions were also attempted, as described below.

Time-series in Figure 7 show when these 19 stations were built and then came online. In some cases; data gaps of significant lengths occurred and these also can be clearly seen in these time series. For some of these gaps, the data were collected at some time after initial near-real-time processing; these data have not yet been reprocessed. At station GMRC, the antenna progressively failed beginning in January 2000 and we replaced it in May 2000. These data are no good and have been removed. Other data that have been removed are occasional outliers. All data that have been removed from our analysis and plots are listed specifically in Table 2. We also note that at time 2000.46 (day 167) our plots represent a change from rapid orbit solutions (prior to day 167) to precise solutions from that date through the present.

\section{Discussion}

Following the 1992 Landers sequence, several modes of transient postseismic deformation are thought to have occurred, as described extensively by Shen et al. (1994), Massonnet et al. (1996), Peltzer et al. (1996, 1998), Bock et al. (1997), Savage and Svarc (1997), Deng et al. (1998), and Pollitz et al. (2000). It is therefore reasonable to expect that some similar modes of postseismic deformation might be present in the time series presented here. The 1999 Hector Mine earthquake, however, was significantly smaller in moment release than the Landers main shock, and therefore appears to have produced a considerably less complex postseismic deformation field. This may also be a consequence of lesser fault-zone interaction or complexity in the case of the Hector Mine rupture.

We examine those SCIGN stations that are within about $80 \mathrm{~km}$ of the event (approximately twice the fault length). Of these 19 sites, 8 were running through the coseismic and postseismic interval and captured the earliest postseismic deformation, whereas 11 were installed after the event and missed from as little as 2 days to as much as 67 days after the event. In our other SCIGN time-series, not presented here (but available from http://pasadena.wr.usgs.gov/scign/ Analysis/), many sites show no significant change in station velocity due to the Hector Mine earthquake. That is, many stations show a coseismic shift, but evidently show linear behavior before and after the event (at the level of resolution we obtained).

\section{Temporal Changes}

In the SCIGN time-series we present for these closest 19 sites, in some cases there is only marginal evidence for a change in rate or any transient behavior (e.g., BMHL, BSRY, OPBL, OPCP, and RDMT). In general, the east and vertical components of all 19 sites fail to show convincing evidence for transient motions that rise above the noise level in the data. One exception to this is the apparent change in motion seen in the east-west component of station OPRD a few weeks after the earthquake. There is, however, evidence for anomalous temporal variation in postseismic motion for a 
(a)
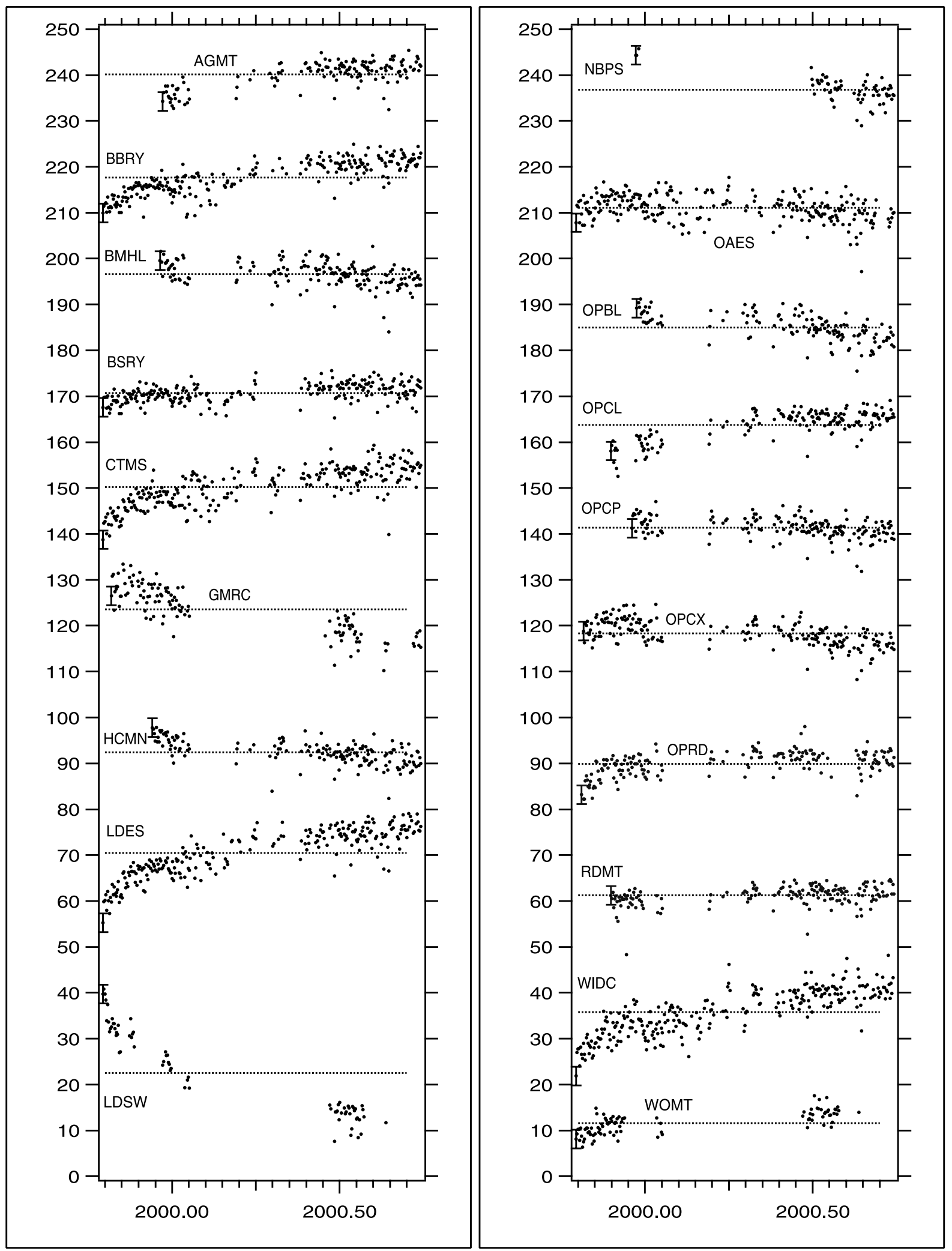

Figure 7. Station time-series for all 19 stations in Table 1. A representative error bar is shown on the first data point of each series. (a) North-south component (north is up). (Continues on next two pages.) 
(b)

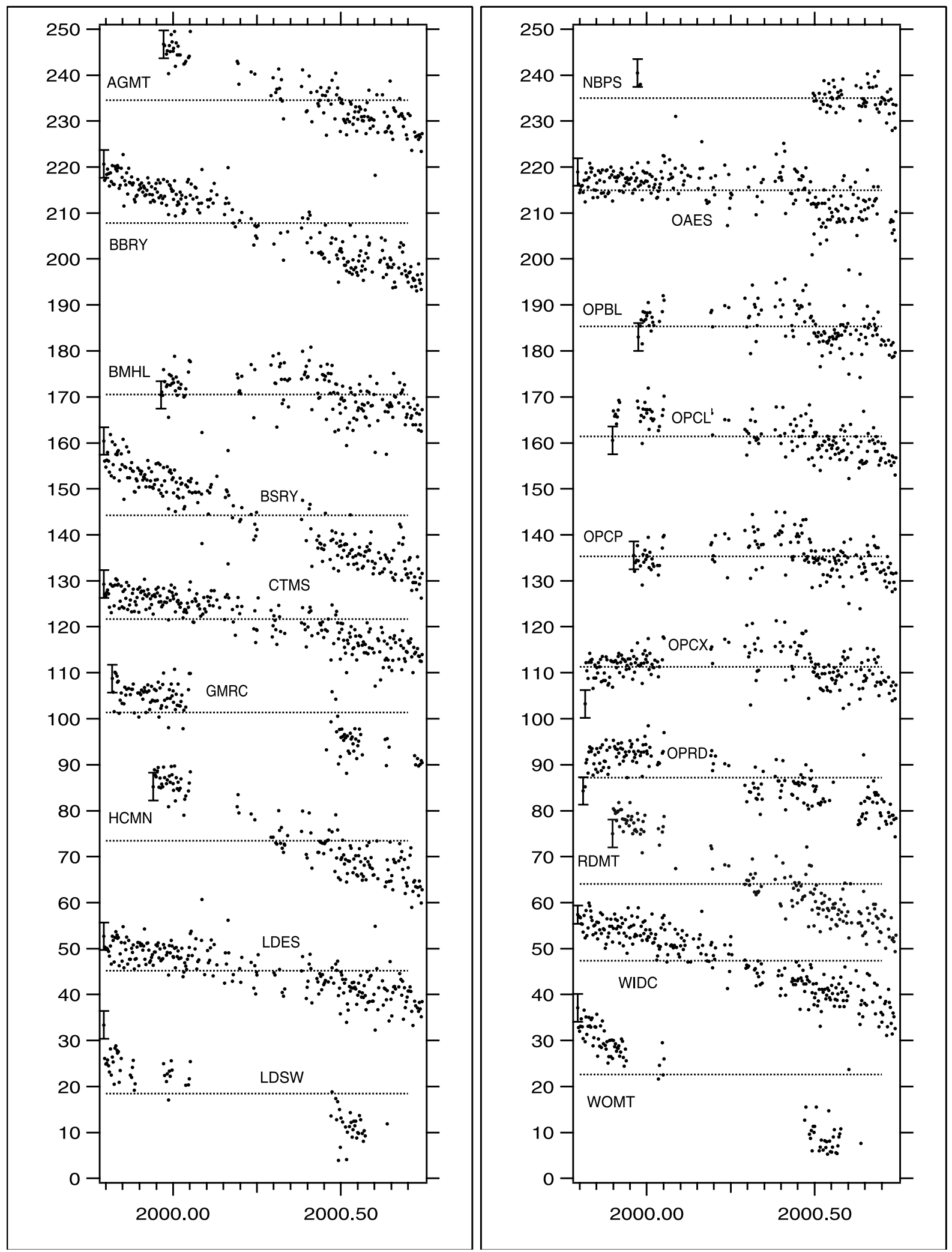

Figure 7. (continued) (b) East-west component (east is up). 
(c)
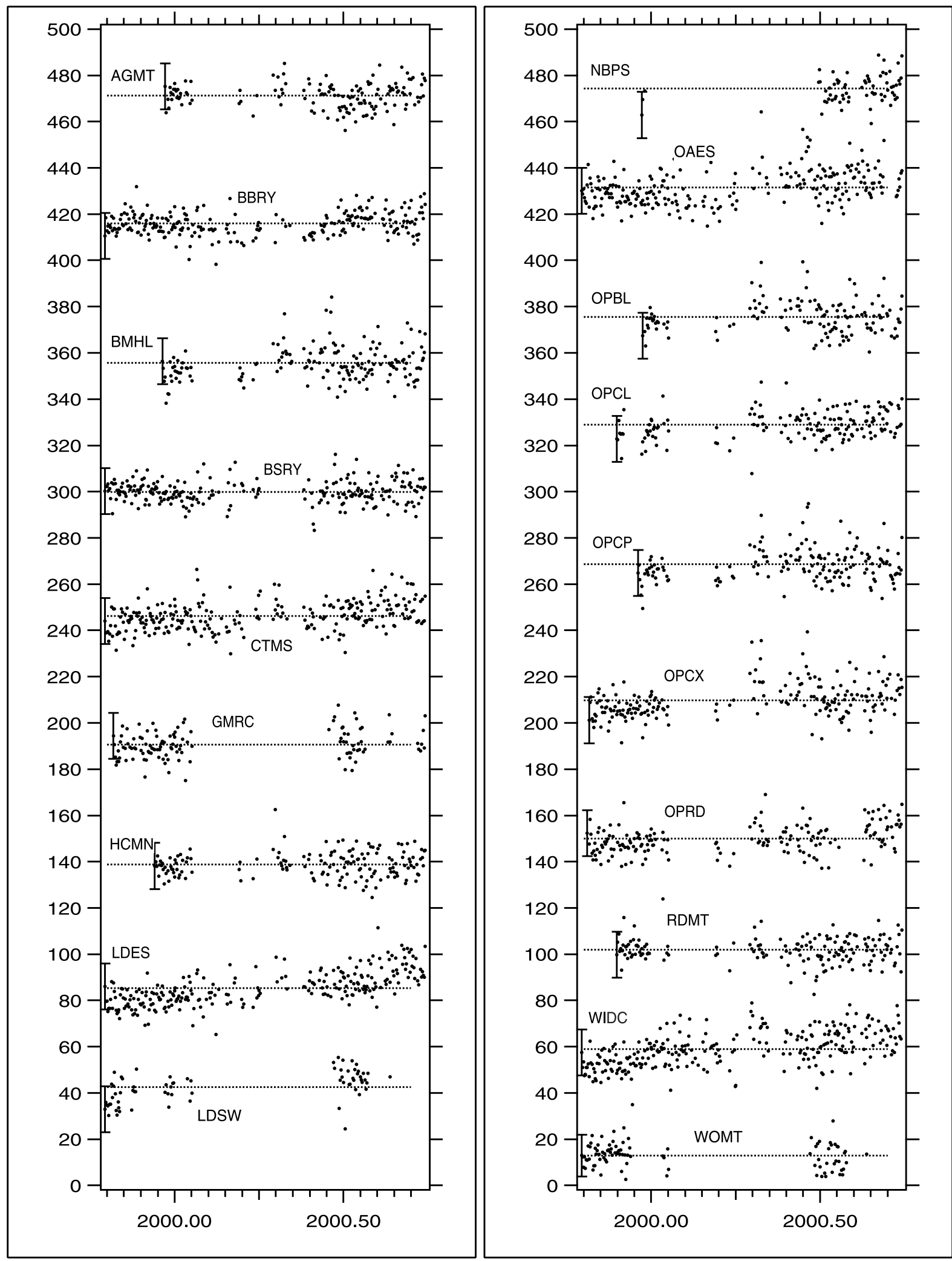

Figure 7. (continued) (c) Up-down component (up is up). 
Table 1

SCIGN Continuously Operating GPS Station Names and Locations for the 19 Southern California Sites Selected for Use in This Study

\begin{tabular}{llcc}
\hline Site & \multicolumn{1}{c}{ Name } & Latitude & Longitude \\
\hline AGMT & Argos Mountain & 34.59427703 & -116.4293650 \\
BBRY & Big Bear Road Yard & 34.26427357 & -116.8842275 \\
BMHL & BEARMAT Hill & 34.25144054 & -116.0529648 \\
BSRY & Barstow Road Yard & 34.91860727 & -117.0119790 \\
CTMS & La Contenta Middle School & 34.12409573 & -116.3704123 \\
GMRS & Granite Mtn. Research Ctr. & 34.78399357 & -115.6602158 \\
HCMN & Hector Mine & 34.75476928 & -116.4300611 \\
LDES & Landers Elementary School & 34.26733456 & -116.4327900 \\
LDSW & Ludlow South West & 34.69950000 & -116.2092000 \\
NBPS & Noble Pass NFA & 34.50861779 & -116.1481590 \\
OAES & Oasis Elementary School & 34.14100059 & -116.0677230 \\
OPBL & OP Bullion & 34.36987797 & -115.9180438 \\
OPCL & OP Creole & 34.42771153 & -116.3054436 \\
OPCP & OP Crampton & 34.36712479 & -116.0833590 \\
OPCX & OP Cross & 34.43007778 & -116.1494707 \\
OPRD & OP Round & 34.53302691 & -116.2922655 \\
RDMT & Rodman Mountain & 34.64393575 & -116.6246724 \\
WIDC & Wide Canyon & 33.93475244 & -116.3917678 \\
WOMT & West Ord Mountain & 34.66860000 & -116.9318000 \\
\hline
\end{tabular}

Table 2

Station Information Summary

\begin{tabular}{lrccccc}
\hline \multicolumn{1}{c}{ Site } & $\begin{array}{r}\text { No. } \\
\text { Obs. }\end{array}$ & $\begin{array}{c}\text { Start time after } \\
\text { earthquake (yrs) }\end{array}$ & $\begin{array}{c}\text { Time span } \\
\text { (yrs) }\end{array}$ & & Omitted Observations \\
\hline AGMT & 139 & 0.181 & 0.77 & 2000.3119 & 2000.6044 & \\
BBRY & 235 & 0.003 & 0.95 & 1998.9304 & & \\
BMHL & 163 & 0.173 & 0.78 & 2000.3119 & 2000.5960 & 2000.6044 \\
BSRY & 230 & 0.003 & 0.95 & 1999.2160 & & \\
CTMS & 254 & 0.003 & 0.95 & 2000.3119 & & \\
GMRC & 119 & 0.028 & 0.92 & 1999.8161 & 2000.1614 & through 2000.4108 \\
HCMN & 157 & 0.150 & 0.80 & 2000.3119 & 2000.6044 & 2000.6294 \\
LDES & 243 & 0.003 & 0.95 & 2000.6044 & & \\
LDSW & 70 & 0.003 & 0.84 & & & \\
NBPS & 68 & 0.181 & 0.77 & & & \\
OAES & 240 & 0.003 & 0.95 & 2000.6044 & & \\
OPBL & 133 & 0.184 & 0.77 & 2000.3119 & 2000.5960 & 2000.6044 \\
OPCL & 151 & 0.107 & 0.84 & 2000.3119 & 2000.6044 & \\
OPCP & 161 & 0.170 & 0.78 & 2000.3119 & 2000.3384 & 2000.5960 \\
OPCX & 198 & 0.025 & 0.93 & 2000.3119 & 2000.5960 & 2000.6044 \\
OPRD & 174 & 0.019 & 0.93 & & & \\
RDMT & 161 & 0.107 & 0.84 & 2000.3119 & 2000.6044 & \\
WIDC & 261 & 0.003 & 0.95 & 2000.6044 & & \\
WOMT & 91 & 0.003 & 0.84 & & & \\
\hline
\end{tabular}

Hector Mine earthquake time: 1999.7912

Omitted observations an data outliers removed from plots and from velocity calculations, etc.

few stations. Most prominently, these include the north components at LDSW (15-20 mm southward motion within the first few weeks), LDES (10 mm northward motion within the first 3 weeks), and OPRD (10 mm northward and eastward within the first few weeks to 2 months). Other sites (e.g., AGMT, BBRY, CTMS, GMRC, HCMN, OAES, OPCL, and OPCX) lie in between these extremes. While their data might be fit in a statistically satisfactory manner using a simple linear function, visual inspection of the data indicates that more rapid deformation may have occurred soon after the earthquake. That is, for these sites, while statistically the data may not require any more complicated function for explanation, we nevertheless did fit both exponential curves (results not presented) and piecewise linear fits to these data (Table 4). For the three sites that clearly display temporally varying rates of motion (LDES, LDSW, and OPRD), as well as for all of the other sites, we evaluated the form of these rate changes and their statistical significance. 
Table 3

Best-Fitting Velocities (Shown in Fig. 1)

\begin{tabular}{|c|c|c|c|c|c|c|c|c|c|}
\hline Site & $\begin{array}{l}\text { North Slope } \\
(\mathrm{mm} / \mathrm{yr})\end{array}$ & $\begin{array}{l}\text { North rms } \\
\quad(\mathrm{mm})\end{array}$ & $\begin{array}{l}\text { North Slope sd } \\
\quad(\mathrm{mm} / \mathrm{yr})\end{array}$ & $\begin{array}{l}\text { East Slope } \\
(\mathrm{mm} / \mathrm{yr})\end{array}$ & $\begin{array}{c}\text { East rms } \\
(\mathrm{mm})\end{array}$ & $\begin{array}{l}\text { East Slope sd } \\
\quad(\mathrm{mm} / \mathrm{yr})\end{array}$ & $\begin{array}{l}\text { Up Slope } \\
(\mathrm{mm} / \mathrm{yr})\end{array}$ & $\begin{array}{l}\text { Up rms } \\
(\mathrm{mm})\end{array}$ & $\begin{array}{l}\text { Up Slope sd } \\
(\mathrm{mm} / \mathrm{yr})\end{array}$ \\
\hline AGMT & 8.2 & 2.1 & 0.7 & -24.2 & 3 & 1.2 & 0.1 & 5.5 & 4.1 \\
\hline BBRY & 9.9 & 2.1 & 0.4 & -24.9 & 2.7 & 0.6 & 3.0 & 4.9 & 2.0 \\
\hline BMHL & -4.6 & 2.5 & 0.7 & -9.6 & 3.9 & 1.1 & 5.9 & 8.3 & 3.7 \\
\hline BSRY & 2.9 & 1.8 & 0.4 & -27.3 & 3.1 & 0.6 & 0.1 & 4.9 & 2.0 \\
\hline CTMS & 10.3 & 2.8 & 0.4 & -15.9 & 2.8 & 0.7 & 7.5 & 5.8 & 2.1 \\
\hline GMRC & -14.5 & 2.7 & 0.6 & -16.4 & 2.9 & 1.0 & 4.7 & 5.8 & 3.1 \\
\hline $\mathrm{HCMN}$ & -6.2 & 2.1 & 0.6 & -29.6 & 3.2 & 1.0 & 1.7 & 5.4 & 3.3 \\
\hline LDES & 14.0 & 2.7 & 0.4 & -13.7 & 2.8 & 0.7 & 16.0 & 5.4 & 2.1 \\
\hline LDSW & -26.9 & 3.1 & 0.7 & -19.6 & 2.9 & 1.1 & 10.8 & 5.6 & 3.7 \\
\hline NBPS & -13.1 & 2.1 & 1.6 & -5.2 & 2.5 & 2.7 & 8.7 & 5.6 & 9.1 \\
\hline OAES & -3.0 & 2.7 & 0.4 & -9.7 & 3.8 & 0.7 & 10.1 & 6.9 & 2.3 \\
\hline OPBL & -8.1 & 2.4 & 0.8 & -8.2 & 3.6 & 1.3 & 0.8 & 7.2 & 4.3 \\
\hline OPCL & 9.0 & 2.2 & 0.6 & -11.9 & 2.8 & 1.1 & 7.2 & 5.6 & 3.5 \\
\hline OPCP & -3.8 & 2.2 & 0.7 & -4.0 & 4.1 & 1.1 & 4.8 & 7.8 & 3.6 \\
\hline OPCX & -5.2 & 2.3 & 0.4 & -2.6 & 3.5 & 0.8 & 8.9 & 6.9 & 2.4 \\
\hline OPRD & 4.1 & 2.4 & 0.5 & -14.3 & 3.2 & 0.8 & 7.1 & 6.6 & 2.6 \\
\hline RDMT & 2.3 & 1.8 & 0.5 & -30.7 & 2.8 & 0.9 & -1.4 & 5.5 & 3.0 \\
\hline WIDC & 13.5 & 3 & 0.4 & -22.7 & 3 & 0.6 & 13.9 & 6.5 & 2.1 \\
\hline WOMT & 5.2 & 1.7 & 0.5 & -32.8 & 2.5 & 0.9 & -2.4 & 5.1 & 3.2 \\
\hline
\end{tabular}

Slopes (velocity components), root mean square (rms) scatter, and standard deviations (sd) in slopes estimated by least-squares fits to north, east, and up components for 19 sites.

We experimented with three functions: linear, piecewise linear, and, for the north component only, linear plus an exponential. The linear plus exponential $\left(A+B \mathrm{e}^{C t}\right)$ model fit very poorly, since the transients in the detrended north components are not smooth enough. The piecewise linear function (1999.794-1999.901, 1999.901-1999.983, and 1999.983-1999.75) fit the north components better. A $\chi^{2}$ test indicates that only for stations LDES, LDSW, and OPRD is the piecewise linear fit better than the simple linear fit over the entire time period. Tables 3 and 4 and Figures 1, 7, 8, and 9 show these two models for the postseismic time series.

These results indicate several interesting points. First, when deploying a network in response to an earthquake of this size, it is important to realize that the resulting postseismic motions may be at the centimeter-per-few-months scale. Thus, the signals we wish to measure are small, and when fitting various functions to the postseismic data, it is vital to have the best possible results- the less scatter, the better confidence one can have in the nature of the temporal variation in the data. For these reasons, one should err toward building more stable monumentation rather than less. Of course, having pre-existing continuously operating GPS stations (with top-grade monuments and GPS hardware, etc.) near future earthquakes would be the ideal way to fully capture preseismic, coseismic, and postseismic signals. We were fortunate to capture the Hector Mine earthquake with the several new SCIGN stations that were at close enough range to record the signals presented here. We clearly see that in deploying new stations, there are diminishing returns with increasing time elapsed since the earthquake. Those sites put in most recently leave us speculating about what the earlier data would have looked like, if only we had been able to set them up sooner; however, we feel that it would not have been as beneficial to install many stations quickly if they had to be of much lower quality.

The velocities of even our later-installed sites (e.g., OPBL and BMHL) are clearly anomalous, however, with respect to the expected secular velocities in this area. These sites are observed now to be moving northward at a rate of 9 to $12 \mathrm{~mm} / \mathrm{yr}$ (Figs. 10 and 11), whereas their secular velocities (prior to the Landers sequence) were within $3.5 \mathrm{~mm} /$ yr of the North American plate rate (discussed further below). Several years hence, we shall presumably see the velocities at these sites restored to their secular rates (which, for all sites except OPCL, we will have to model). The time scale with which this occurs will eventually give further insights into longer time scale stress-relaxation processes. So, although it seems discouraging to see evidently linear timeseries from these sites, they do hold promise of helping show longer-period transients with time. That is, with 1 year of data, signals with time constants of more than a few months would not likely be evident, but several years of additional observations will perhaps make this much clearer than it is today. Furthermore, it is common in geodetic time-series to have nontectonic station motions with an approximately annual period. For this reason, some concern is warranted regarding what can safely be interpreted from a single year of data.

We have included station WIDC because it appears to show time-varying motion in the north component, about 10 $\mathrm{mm}$ within the first 6 to 8 weeks. In this case, the site is more distant from the Hector Mine earthquake than other sites (e.g., LDES) with similar transient motions. The WIDC site, however, is located close to other possible sources of 
1416 K. W. Hudnut, N. E. King, J. E. Galetzka, K. F. Stark, J. A. Behr, A. Aspiotes, S. vanWyk, R. Moffitt, S. Dockter, and F. Wyatt

Table 4

Piecewise Linear Fits to the Data from Three Time Intervals after the Hector Mine Earthquake, Estimated by Least Squares Fits to the Postseismic Data from the N.E. and U. Components for All 19 Sites

\begin{tabular}{|c|c|c|c|c|c|c|c|}
\hline Site & Points & $\begin{array}{c}\text { North Slope } \\
(\mathrm{mm} / \mathrm{yr})\end{array}$ & $\begin{array}{l}\text { North Slope sd } \\
\quad(\mathrm{mm} / \mathrm{yr})\end{array}$ & $\begin{array}{c}\text { East Slope } \\
(\mathrm{mm} / \mathrm{yr})\end{array}$ & $\begin{array}{l}\text { East Slope sd } \\
\quad(\mathrm{mm} / \mathrm{yr})\end{array}$ & $\begin{array}{l}\text { Up Slope } \\
(\mathrm{mm} / \mathrm{yr})\end{array}$ & $\begin{array}{l}\text { UP Slope sd } \\
(\mathrm{mm} / \mathrm{yr})\end{array}$ \\
\hline & \multicolumn{3}{|c|}{ 1999.794-1999.901 } & \multicolumn{4}{|c|}{ First time period } \\
\hline AGMT* & none & none & none & none & none & none & none \\
\hline BBRY & $0-39$ & 46.9 & 8.2 & -37.3 & 14.3 & 39.5 & 47.5 \\
\hline BMHL* & none & none & none & none & none & none & none \\
\hline BSRY & $0-39$ & 21.5 & 8.1 & -52.7 & 13.7 & -0.7 & 46.7 \\
\hline CTMS & $0-39$ & 64.5 & 8.9 & -19.0 & 16.6 & 46.7 & 50.3 \\
\hline GMRC & $0-24$ & 21.4 & 16.4 & -37.4 & 29.0 & 38.0 & 86.5 \\
\hline HCMN & none & none & none & none & none & none & none \\
\hline LDES & $0-39$ & 81.9 & 8.9 & -18.0 & 16.6 & -17.6 & 50.2 \\
\hline LDSW & $0-25$ & -73.8 & 12.5 & -40.4 & 22.8 & 76.6 & 70.6 \\
\hline NBPS* & none & none & none & none & none & none & none \\
\hline OAES & $0-39$ & 39.4 & 9.4 & 3.6 & 18.6 & 13.2 & 51.4 \\
\hline OPBL* & none & none & none & none & none & none & none \\
\hline OPCL & none & none & none & none & none & none & none \\
\hline OPCP* & none & none & none & none & none & none & none \\
\hline OPCX & $0-31$ & 38.9 & 13.2 & 0.7 & 24.4 & 22.3 & 70.8 \\
\hline OPRD & $0-29$ & 87.3 & 14.8 & 40.0 & 25.1 & 1.0 & 82.6 \\
\hline RDMT & none & none & none & none & none & none & none \\
\hline WIDC & $0-39$ & 66.0 & 8.7 & -29.4 & 15.1 & 24.1 & 49.0 \\
\hline \multirow[t]{41}{*}{ WOMT } & $0-39$ & 33.3 & 8.1 & -63.9 & 13.7 & 41.0 & 47.5 \\
\hline & \multicolumn{3}{|c|}{ 1999.901-1999.983 } & \multicolumn{4}{|c|}{ Second time period } \\
\hline & none & none & none & none & none & none & none \\
\hline & $39-68$ & 24.1 & 12.3 & -12.9 & 21.5 & -33.8 & 71.5 \\
\hline & none & none & none & none & none & none & none \\
\hline & $39-68$ & 9.4 & 12.2 & -14.2 & 20.8 & -46.2 & 70.6 \\
\hline & $39-68$ & 14.9 & 13.4 & -20.2 & 23.7 & -17.4 & 75.1 \\
\hline & $24-53$ & -28.0 & 15.0 & -5.8 & 25.2 & -27.9 & 77.7 \\
\hline & $0-14$ & -19.1 & 37.1 & -25.9 & 65.8 & -149.0 & 206.0 \\
\hline & $39-68$ & 30.4 & 13.3 & -18.4 & 23.6 & 3.0 & 75.0 \\
\hline & $25-29^{1}$ & -25.8 & 22.3 & 22.2 & 40.2 & -124.6 & 128.0 \\
\hline & none & none & none & none & none & none & none \\
\hline & $39-68$ & 7.1 & 14.3 & -8.6 & 25.1 & -7.6 & 76.8 \\
\hline & none & none & none & none & none & none & none \\
\hline & $1-12$ & 36.6 & 16.9 & 15.7 & 27.7 & -60.3 & 95.4 \\
\hline & none & none & none & none & none & none & none \\
\hline & $31-60$ & 11.6 & 14.0 & 2.5 & 24.9 & -18.7 & 75.4 \\
\hline & $29-57$ & 20.4 & 14.2 & -8.9 & 24.1 & -43.2 & 78.5 \\
\hline & $1-30$ & 13.5 & 13.1 & -44.1 & 23.8 & -26.2 & 74.7 \\
\hline & $39-68$ & 64.7 & 13.3 & -3.4 & 23.2 & 51.7 & 74.4 \\
\hline & $39-53$ & 19.9 & 36.0 & -67.1 & 63.3 & -10.9 & 210.0 \\
\hline & \multicolumn{3}{|c|}{ 1999.983-1999.75 } & \multicolumn{4}{|c|}{ Third time period } \\
\hline & none & none & none & none & none & none & none \\
\hline & $68-234$ & 10.1 & 0.5 & -27.2 & 0.8 & 6.7 & 2.9 \\
\hline & none & none & none & none & none & none & none \\
\hline & $68-229$ & 3.1 & 0.5 & -28.6 & 0.8 & 1.9 & 2.9 \\
\hline & $68-253$ & 8.7 & 0.6 & -18.4 & 0.8 & 7.5 & 3.1 \\
\hline & $53-118$ & -12.3 & 1.0 & -18.5 & 1.6 & 3.4 & 5.0 \\
\hline & $14-156$ & -5.0 & 0.8 & -29.3 & 1.3 & 1.1 & 4.1 \\
\hline & $68-242$ & 11.1 & 0.6 & -15.6 & 0.9 & 17.2 & 3.2 \\
\hline & $29-69$ & -18.6 & 1.43 & -21.2 & 2.3 & 8.1 & 7.5 \\
\hline & none & none & none & none & none & none & none \\
\hline & $68-239$ & -3.5 & 0.6 & -13.5 & 0.9 & 12.6 & 3.4 \\
\hline & none & none & none & none & none & none & none \\
\hline & $12-150$ & 8.0 & 0.8 & -12.9 & 1.3 & 6.0 & 4.2 \\
\hline & none & none & none & none & none & none & none \\
\hline & 60-197 & -5.4 & 0.8 & -7.7 & 1.3 & 5.2 & 4.1 \\
\hline & $57-173$ & 1.4 & 0.8 & -18.3 & 1.4 & 9.5 & 4.4 \\
\hline & $30-160$ & 2.5 & 1.0 & -29.4 & 1.6 & 2.0 & 5.2 \\
\hline & $68-260$ & 13.2 & 0.5 & -24.6 & 0.8 & 9.5 & 2.9 \\
\hline & 53-90 & 5.4 & 1.5 & -31.3 & 2.5 & 1.7 & 8.7 \\
\hline
\end{tabular}




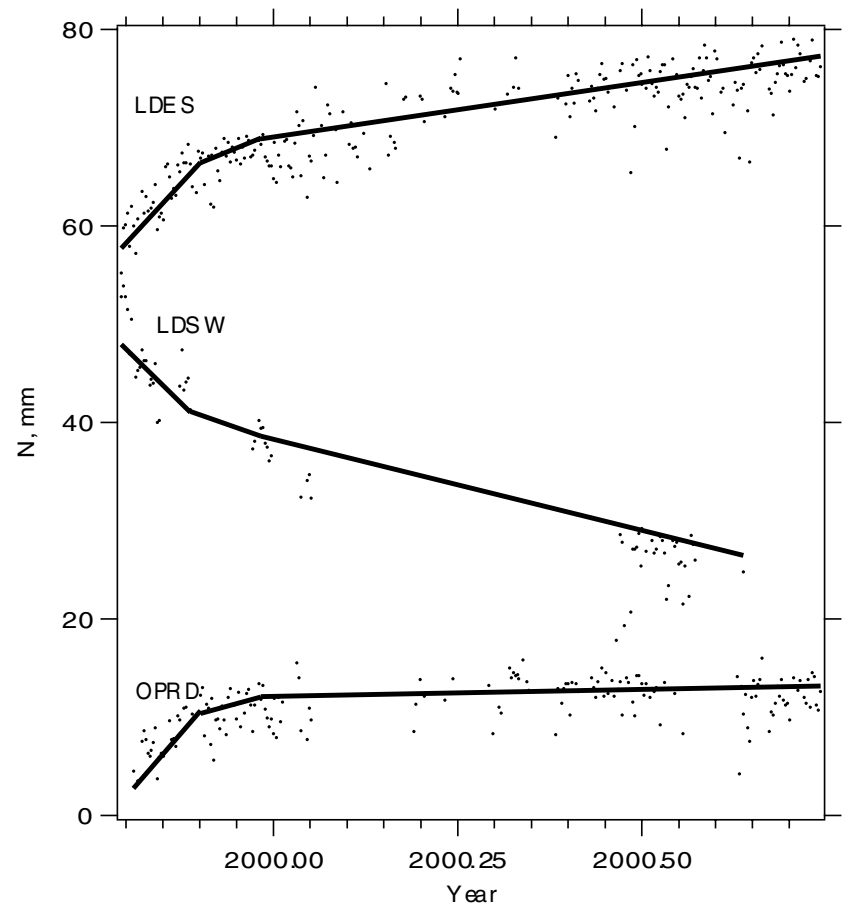

Figure 8. Piecewise linear fits to data from a subset of sites that show the clearest evidence for temporal variation in deformation following the earthquake. We statistically evaluated linear and exponential fits to the data, but these piecewise linear curves fit the data best. Station LDES was online before the event and operated continuously throughout the postseismic period, whereas LDSW and OPRD were deployed soon after the earthquake. Table 4 gives values obtained and the best-fitting piecewise linear parameters estimated for data from all 19 of the sites.

deformation: the San Andreas fault and the set of northerly oriented faults in the vicinity of the 1992 Joshua Tree earthquake (Rymer, 2000). On the basis of SAR interferometry, Sandwell et al. (2000) reported that creep occurred on the San Andreas fault during the same approximate time frame as the Hector Mine mainshock. Such triggered slip is a wellknown phenomenon that has been repeatedly observed along this section of the San Andreas fault and other faults in the Salton Trough (e.g., Hudnut and Clark, 1989; Rymer, 2000; Rymer et al., 2002). It is plausible that the transient deformation observed at station WIDC may be attributed to motion on the San Andreas fault source, rather than a source near the Hector Mine fault ruptures. It may be more consistent with our GPS results and those of Owen et al. (2002), as well as with the SAR interferometry results, to fit the observed motion at WIDC with an aseismic source along the southern San Andreas rather than by placing more slip at depth in the Hector Mine source region. Since this seemingly discordant motion occurs on just this one site, we choose not to attempt to interpret this any further.

In general, since the mainshock, those stations within a few kilometers of the surface rupture (OPRD, OPCX, NBPS,
OPCL, and OPCP) have not moved as much as those stations that lie 5 to $15 \mathrm{~km}$ away from the source (Fig. 1). This seems to indicate that the main, long time-constant postseismic deformation has a relatively deep source. It is possible that the motion observed at LDSW, which shows a relatively large and rapid transient deformation, may be associated with aftershocks (e.g., Hauksson et al., 2002) or with a prominent deformation feature seen in postseismic SAR interferograms (e.g., Pollitz et al., 2001) south of Lavic Lake, near the northern end of the 1999 Hector Mine rupture.

\section{Spatial Changes}

In Figure 1, we have presented the velocities as they were computed without further analyzing these data or correcting them for other effects. These velocities are affected by secular deformation as documented, for example, by Feigl et al. (1993) and the second version of the SCEC crustal motion map (http://www.scecdc.scec.org/group_e/release. $v 2 /)$. Also, the effects of the Landers earthquake postseismic deformation field are large in the region studied (e.g., Peltzer et al., 1996, 1998; Deng et al., 1998; Pollitz et al., 2000). The results in Figure 1, therefore, must be corrected for these effects. A long-term record of pre-earthquake site-position information, however, is available only for observation post Creole (OPCL). At this mountaintop site, the USGS crustal strain project made geodolite and field GPS observations frequently over the years prior to the Hector Mine earthquake (e.g., Savage et al., 1990, 1993; Sauber et al., 1994). For those SCIGN stations that were recording data prior to the Hector Mine earthquake, too short a time span of data is available to reliably estimate a pre-earthquake site velocity. Except for OPCL, no pre-earthquake site velocities are available. The best we can do at this time, therefore, is to interpolate velocities measured at nearby sites, before the Landers sequence (from the SCEC crustal motion map), and then use modeled displacements for these stations between the times Landers and Hector Mine earthquakes from Pollitz et al. (2000), and then remove these corrections from each site's velocity. We show our interpolated correction values in Table 5 and Figure 10. We do not remove these velocity corrections from the time-series in Figure 7. It may be possible, in the future, to interpolate these sites' velocities better by using even more densely spaced measurements of the interseismic velocity field in the epicentral area. This will be feasible once all data recently provided by the U.S. Marine Corps have been assimilated into a future release of the SCEC crustal motion map velocity field. After removing the secular field and Landers postseismic model, the remaining velocity field contained a large residual common-mode westward velocity and a common southward motion at the two sites farthest from the event, GMRC and BBRY. We empirically removed these evidently systematic errors by removing a common vector from all of the velocities (13.7 $\mathrm{mm} / \mathrm{yr}$ east; $16.3 \mathrm{~mm} / \mathrm{yr}$ north), so as to reduce the residual velocities of GMRC and BBRY to nearly zero.

The remaining velocity field has been constructed based 

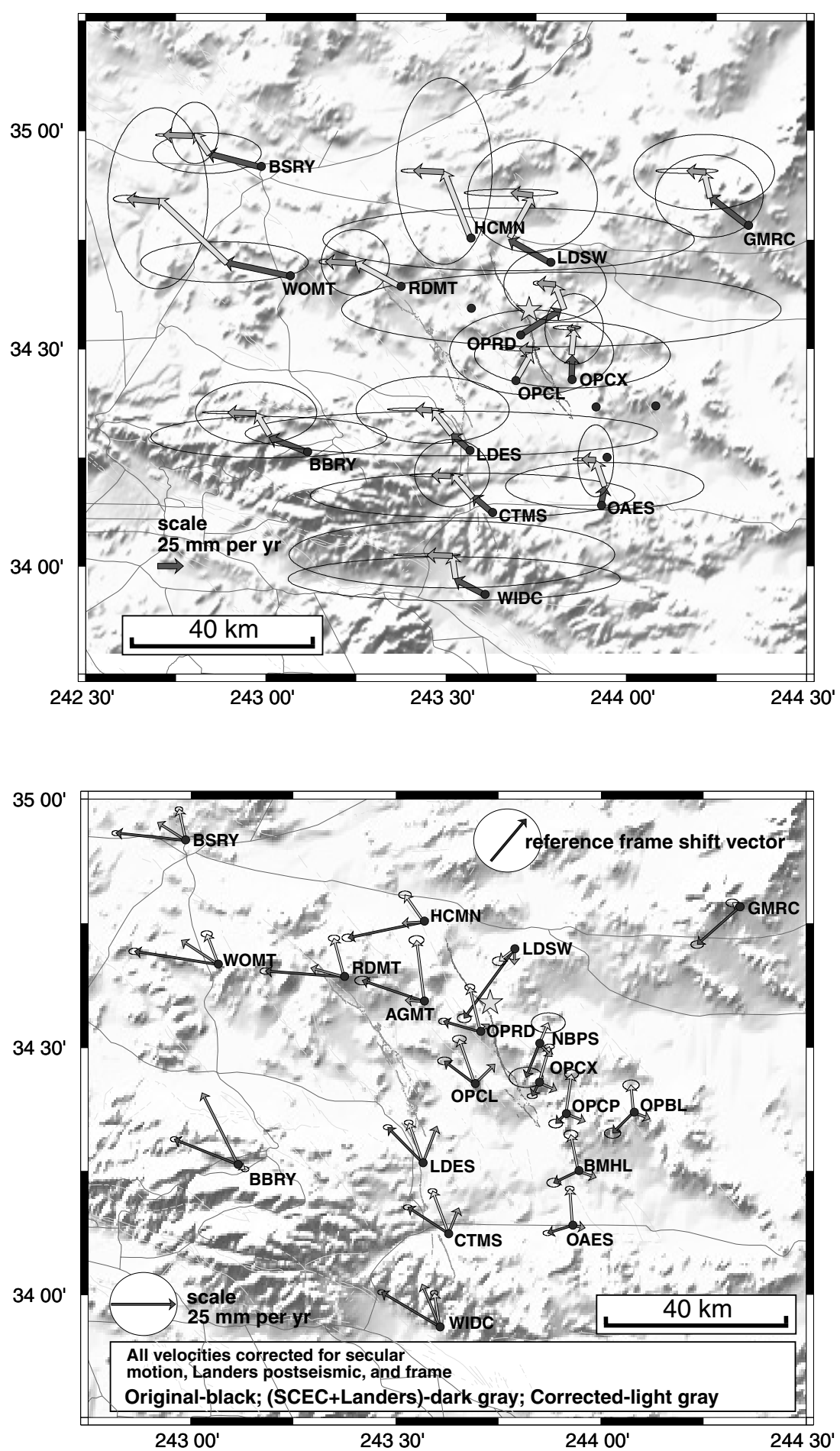

Figure 9. Piecewise linear fits, as listed in Table 4, to show how observed velocities vary with time at several sites. Temporal variation at both LDSW and OPRD is the most distinctive. Dark gray vectors show the velocity observed from time 1999.794 to 1999.901 , light gray vectors show the velocity from 1999.901 to 1999.983 , and intermediate gray vectors show the velocity from 1999.983 to 2000.750 . As shown by the 1-standard-deviation error ellipses, the vectors from the last time slice are based on a longer time and are therefore generally the best resolved.
Figure 10. Map showing the three corrections made to each site's displacement vector and the resulting corrected view of the postseismic displacement field. Station velocities were adjusted to account for secular velocities (interpolated from the second version of the Southern California Earthquake Center [SCEC] crustal motion map), for the Landers sequence postseismic velocities (Pollitz et al., 2000), and for a translation in north and east to remove a common residual velocity at sites GMRC and BBRY (of $13.7 \mathrm{~mm} / \mathrm{yr}$ east; $16.3 \mathrm{~mm} / \mathrm{yr}$ north). The dark gray vectors are as given in Table 3 and Fig. 1; light gray vectors are the sum of secular and Landers postseismic contributions. The black arrow in the upper right shows the common vector removed from all sites. The resulting corrected postseismic displacement vectors are shown in light gray (with the same errors as listed in Table 3, before making the corrections). on several key assumptions; (1) that the SCEC crustal motion model and our interpolation of it are correct and adequate, (2) that the Pollitz et al. (2000) Landers postseismic model is adequate for deformation in the area covered here, and (3) that the empirical removal of a common-mode velocity is valid. The resultant velocity field now can be interpreted, keeping in mind these possible limitations. First, our results indicate that these velocities are asymmetric about the rup- ture, and hence are not consistent with a simple doublecouple source, as might be expected if the postseismic signal were attributed to deep $(>15 \mathrm{~km})$ aseismic slip on an elastic dislocation or within a layered but laterally uniform viscoelastic medium (e.g., Pollitz et al., 2001). Instead, the data appear to show a transition in the velocity field, roughly across the Hector Mine rupture. The crust to the west of the fault is moving northwards with respect to crust to the east 


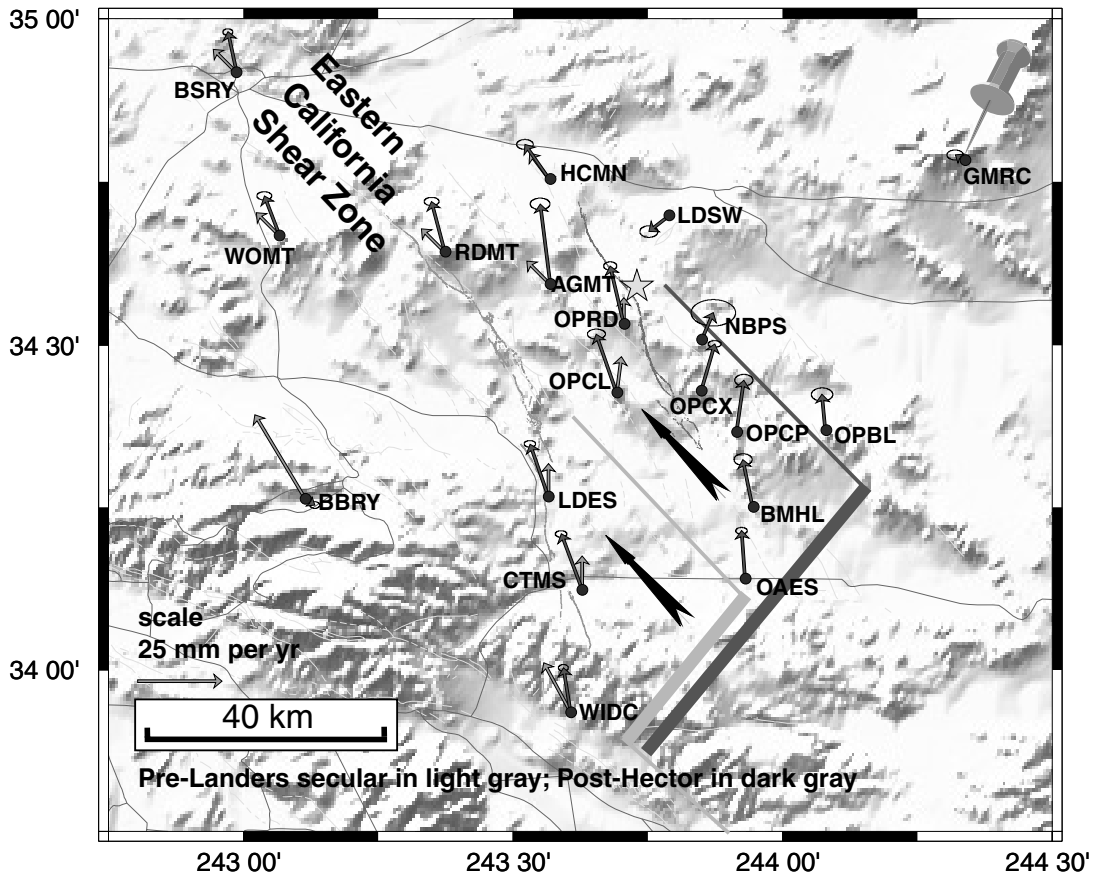

Figure 11. Corrected Hector Mine postseismic velocities (in dark gray), compared with pre-Landers secular velocities (in lighter gray), interpolated from version 2 of the SCEC crustal motion map. The pull-apart feature of Savage et al. (1993) and Johnson et al. (1994) is shown in light gray, trending northeast and connecting the southern San Andreas fault with the eastern California shear zone. This represents a lower crustal zone (below $15 \mathrm{~km}$ depth) accommodating $8 \mathrm{~mm} / \mathrm{yr}$ of northwestoriented extension. We speculatively show a new extension of this feature towards the northeast in darker gray, further illustrated in Fig. 12. We suggest a pull-apart feature that is similar to the one previously proposed, but stepping inboard by $30 \mathrm{~km}$ towards the northeast.

Table 5

Corrections to the Velocities Obtained (Table 3 and Figure 1) to Account For Secular Deformation, Effects of the Landers Sequence, and a Common Mode (Reference Frame) Shift

\begin{tabular}{|c|c|c|c|c|c|c|c|c|c|c|}
\hline \multirow[b]{3}{*}{ Site } & \multicolumn{4}{|c|}{ Corrections to Velocities } & \multicolumn{2}{|c|}{ Sum of Corrections } & \multicolumn{2}{|c|}{ Corrected Velocities } & \multicolumn{2}{|c|}{ Adjusted Velocities } \\
\hline & \multicolumn{2}{|c|}{ SCEC v. 2} & \multicolumn{2}{|c|}{ Pollitz (2000) } & \multirow[b]{2}{*}{ North } & \multirow[b]{2}{*}{ East } & \multirow[b]{2}{*}{ North } & \multirow[b]{2}{*}{ East } & \multirow[b]{2}{*}{ North } & \multirow[b]{2}{*}{ East } \\
\hline & North & East & North & East & & & & & & \\
\hline AGMT & 7.0 & -7.0 & -6.5 & -0.5 & 0.5 & -7.5 & 7.7 & -16.7 & 24.0 & -3.0 \\
\hline BBRY & 25.0 & -15.0 & 3.0 & 1.0 & 28.0 & -14.0 & -18.1 & -10.9 & -1.8 & 2.8 \\
\hline BMHL & 0.0 & 0.0 & -2.5 & 7.0 & -2.5 & 7.0 & -2.1 & -16.6 & 14.2 & -2.9 \\
\hline BSRY & 7.0 & -7.0 & 0.0 & -4.0 & 7.0 & -11.0 & -4.1 & -16.3 & 12.2 & -2.6 \\
\hline CTMS & 10.0 & 0.0 & 0.0 & 4.0 & 10.0 & 4.0 & 0.3 & -19.9 & 16.6 & -6.2 \\
\hline GMRC & 0.0 & 0.0 & 0.0 & 0.0 & 0.0 & 0.0 & -14.5 & -16.4 & 1.8 & -2.7 \\
\hline $\mathrm{HCMN}$ & 8.0 & -6.0 & -8.5 & -2.5 & -0.5 & -8.5 & -5.7 & -21.1 & 10.6 & -7.4 \\
\hline LDES & 10.0 & 0.0 & 4.5 & 5.5 & 14.5 & 5.5 & -0.5 & -19.2 & 15.8 & -5.5 \\
\hline LDSW & 0.0 & 0.0 & -6.0 & 0.0 & -6.0 & 0.0 & -20.9 & -19.6 & -4.6 & -5.9 \\
\hline NBPS & 0.0 & 0.0 & -5.0 & 5.0 & -5.0 & 5.0 & -8.1 & -10.2 & 8.2 & 3.5 \\
\hline OAES & 0.0 & 0.0 & -1.0 & 5.0 & -1.0 & 5.0 & -2.0 & -14.7 & 14.3 & -1.0 \\
\hline OPBL & 0.0 & 0.0 & -2.5 & 6.5 & -2.5 & 6.5 & -5.6 & -14.7 & 10.7 & -1.0 \\
\hline OPCL & 10.8 & 1.4 & -3.0 & 6.5 & 7.8 & 7.9 & 1.2 & -19.8 & 17.5 & -6.1 \\
\hline OPCP & 0.0 & 0.0 & -3.0 & 7.5 & -3.0 & 7.5 & -0.8 & -11.5 & 15.5 & 2.2 \\
\hline OPCX & 0.0 & 0.0 & -3.0 & 7.0 & -3.0 & 7.0 & -2.2 & -9.6 & 14.1 & 4.1 \\
\hline OPRD & 8.0 & 0.0 & -5.0 & 3.5 & 3.0 & 3.5 & 1.1 & -17.8 & 17.4 & -4.1 \\
\hline RDMT & 7.0 & -7.0 & -3.5 & -6.0 & 3.5 & -13.0 & -1.2 & -17.7 & 15.1 & -4.0 \\
\hline WIDC & 14.6 & -7.9 & 2.0 & 1.0 & 16.6 & -6.9 & -3.1 & -15.8 & 13.2 & -2.1 \\
\hline WOMT & 7.0 & -7.0 & 2.5 & -7.5 & 9.5 & -14.5 & $\begin{array}{l}-4.3 \\
-16.3 \text { (avg.) }\end{array}$ & $\begin{array}{l}-18.3 \\
-13.7 \text { (avg.) }\end{array}$ & 12.0 & -4.6 \\
\hline
\end{tabular}

Bold type indicates measured velocity at site.

of the fault. This appears not as a distinct break, but rather a transition zone $(\sim 10 \mathrm{~km}$ wide $)$ of shear along the rupture zone. This pattern of deformation is strongly reminiscent of that seen slightly farther $(\sim 25 \mathrm{~km})$ to the west, prior to the Landers earthquake.
In the region of the Landers sequence and Hector Mine earthquake, a curious pull-apart feature of the secular deformation field was shown to exist; it was noted both by Savage et al. (1993) and Johnson et al. (1994) on the basis of preLanders strain data from the USGS geodolite project. Savage 
et al. (1993) described the feature in a manner subsequently illustrated by Johnson et al. (1994), and we have attempted to recapture that idea in Figure 11. In the Savage et al. (1993) article, deformation was represented as velocities, assuming two stations near Twentynine Palms motions were fixed. In the Johnson et al. (1994) article, the deformation was shown and modeled in terms of strain. The SCEC crustal motion map combined the geodolite data with GPS measurements and applied a North American reference frame, to obtain an absolute velocity for each of the sites. Hence, although the orientation of the motion vectors shown here (based on the SCEC map) differ from the sense of motion in the earlier publications, the data still require a northwest-oriented extension across a northeast-striking opening feature. This pattern of northerly-oriented velocities at sites SANH and OP Creole in the SCEC map is reflected in similarly oriented velocities in our derived post-Hector Mine velocities. The difference is that, following the Hector Mine earthquake, this pattern has migrated northeastward by about 25 to $30 \mathrm{~km}$. This is consistent with an inboard shift of right-lateral shear strain into the continental crust.

Both Savage et al. (1993) and Johnson et al. (1994) specifically interpreted the tectonic significance of this unusual deformation feature as representing the inboard transfer of strike-slip motion from the southern San Andreas fault to the eastern California shear zone (ECSZ). The northeastern extent of this feature was well constrained by their data to lie near the town of Joshua Tree. Sites farther to the east and northeast showed no evidence for the zone to continue farther toward the northeast at that time. Figure 11, however, shows a clear pattern in the Hector Mine postseismic deformation field that is similar to the pre-Landers field. We suggest that this indicates that the same type of mechanism is occurring, only that it is now extending farther inboard. This suggests that a crustal block, measuring approximately 30 $\mathrm{km}$ (from SW to NE) by $50 \mathrm{~km}$ (from SE to NW), that used to move at less than $3.5 \mathrm{~mm} / \mathrm{yr}$ with respect to the North American Plate prior to 1992, is now moving at a rate of approximately $11 \mathrm{~mm} / \mathrm{yr}$ northward (Fig. 12). This crustal deformation then feeds into the ECSZ, and from midway along both the Landers and Hector Mine ruptures there is a transition to northwestward velocities along the ECSZ faults. We find it interesting that the inboard jump of the axis of right-lateral shear strain, $30 \mathrm{~km}$ farther into the continental crust, occurs coincident with the time frame including the Landers and Hector Mine earthquake sequence. Judging from active faults of the area, past motions on these inboardmost faults of the ECSZ had occurred in the past, but at a lower rate than other faults of the ECSZ that lie subparallel (but farther to the southwest).

\section{Conclusions}

Our primary observation is that the temporal and spatial character of the crustal motion velocity field in the vicinity of the Hector Mine earthquake changed after the earthquake. To establish this, we computed station velocities using the 1 year of data collected following the earthquake. It is clear that, after detrending the data by these estimated station velocities, data from several stations still contain statistically significant temporal changes in velocity, which we attribute to postseismic deformation associated with the Hector Mine earthquake. Hence, the temporally decaying signals we hoped and expected to record are indeed present in these data. To ascertain the form of temporal changes, we statistically evaluated this issue and realized that, while exponential curve fits are not defensible, piecewise linear fits are valid. To evaluate spatial changes in the velocity field, we then corrected our estimated velocities using those computed from a model by Pollitz et al. (2000) for postseismic deformation following the 1992 Landers sequence, as well as interseismic rates of deformation interpolated from the SCEC

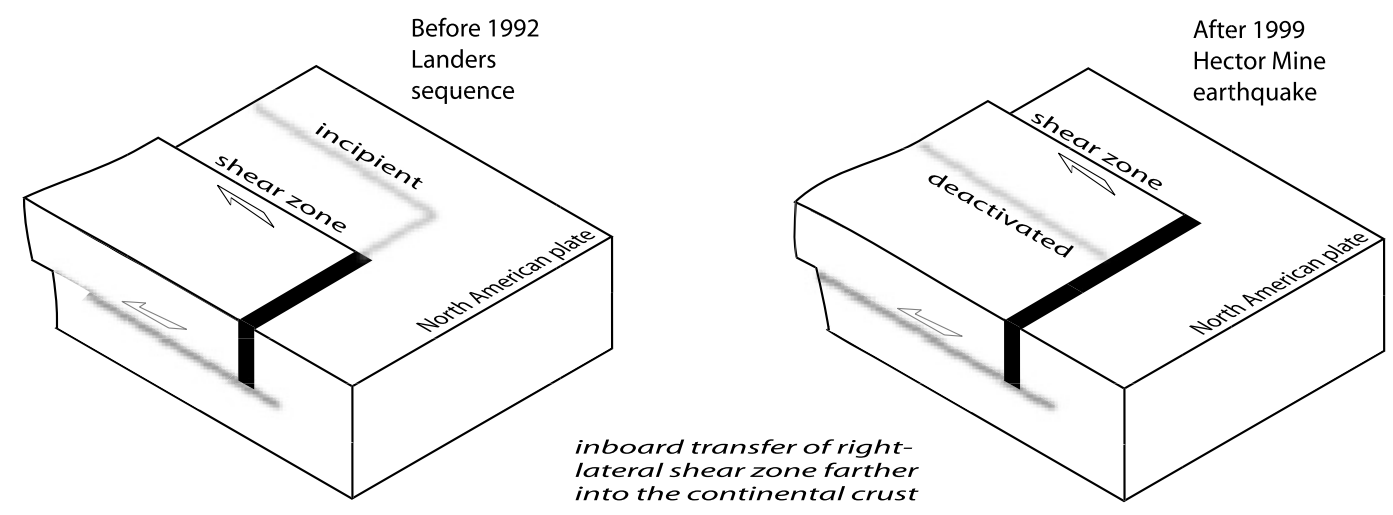

Figure 12. Illustration of time-progressive inboard transfer of right-lateral shear zone. Prior to the 1992 Landers sequence, crustal blocks southwest of those faults that ruptured in 1992 were already moving towards the northwest. After the 1999 Hector Mine earthquake, a block of crustal material farther to the northeast also became entrained in the northwestward motion, pulling away from the North American plate. Right-lateral motion thereby stepped farther inboard, into the continental crust. 
crustal motion map. A common-mode velocity also was identified and removed from the residual velocity field. Spatial variation in the velocity field thus obtained appears inconsistent with a double-couple source for deep slip on or below the Hector Mine earthquake coseismic source zone. Instead, we interpret the postseismic deformation field as indicating an inboard jump of right-lateral shear strain, 30 $\mathrm{km}$ farther into the continental crust than previously noted by Savage et al. (1993) and Johnson et al. (1994).

\section{Acknowledgments}

Without the permission and support of the U.S. Marine Corps Air Ground Combat Center (MCAGCC) in Twentynine Palms, California, we would not have been able to conduct this study. In particular, we thank Lt. Col. James J. Tabak for his support. We also thank Captain Teitzel, Mr. Paul "Kip" Otis-Deihl, the Explosive Ordinance Disposal Section, the Range Operations Section, Range Control, and the command and personnel of MCAGCC for their tremendous assistance and cooperation in facilitating field investigations. We thank W. Karl Gross of the U.S. Geological Survey for exemplary service as scientific operations liaison with MCAGCC, providing tremendous help and insight with all logistical matters in the field, and for arranging aircraft support. We thank CWO4 T. Murphy, 1st Lt. J. Ochwatt, and SPC4 B. V. Cabanban Jr. of the Los Alamitos Army Aviation Support Facility, California Army National Guard, and Landells' Aviation for providing aircraft support. We also thank Duncan Agnew, Don Elliot, and Greg Anderson of Scripps Institution of Oceanography for field logistics and support, Ed Arnitz, Fred Nissen, Chris Mora, John Taylor, and Ryan Densmore of Gradient Engineers, as well as Mike Capriano of GPS Drilling, for their fieldwork. We thank Sue Hough, Mike Bevis, and Mike Rymer for their helpful reviews. We acknowledge the Southern California Integrated GPS Network (SCIGN) and its sponsors, the W. M. Keck Foundation, NASA, NSF, and USGS, for providing funding and support. Southern California Earthquake Center Publication Number 634.

\section{References}

Agnew, D. C., S. Owen, Z.-K. Shen, G. Anderson, J. Svarc, H. Johnson, K. E. Austin, and R. Reilinger (2002). Coseismic displacements from the Hector Mine, California, earthquakes: results from survey-mode GPS measurements, Bull. Seism. Soc. Am. 92, 1355-1364 (this issue).

Beutler, G., and R. Neilan (1997). International GPS Service for Geodynamics, International Association of Geodesy General Assembly, Rio de Janeiro, Brazil, September 3-9, 1997.

Bock, Y., S. Wdowinski, P. Fang, J. Zhang, S. Williams, H. Johnson, J. Behr, J. Gengrich, J. Dean, M. van Domselaar, D. Agnew, F. Wyatt, K. Stark, B. Oral, K. Hudnut, R. King, T. Herring, S. Dinardo, W. Young, D. Jackson and W. Gurtner (1997). Southern California permanent GPS geodetic array: continuous measurements of regional crustal deformation between the 1992 Landers and 1994 Northridge earthquakes, J. Geophys. Res. 102, no. B8, 18,013-18,033.

Deng, J., Gurnis, M., Kanamori, H., Hauksson, E. (1998). Viscoelastic flow in the lower crust after the 1992 Landers, California, earthquake, Science 282, no. 5394, 1689-1692.

Dong, D.-N., and Y. Bock (1989). Global Positioning System network analysis with phase ambiguity resolution applied to crustal deformation studies in California, J. Geophys. Res. 94, 3949-3966.

Dreger, D. S. and A. Kaverina (2000). Seismic remote sensing for the earthquake source process and near-source strong shaking: a case study of the October 16, 1999 Hector Mine earthquake, Geophys. Res. Lett. 27, no. 13, 1941-1944.

Feigl, K., D. C. Agnew, Y. Bock, D.-N. Dong, A. Donnellan, B. H. Hager, T. A. Herring, D. D. Jackson, R. W. King, S. K. Larsen, K. M. Larson,
M. H. Murray, and Z.-K. Shen (1993). Measurement of the velocity field in central and southern California, J. Geophys. Res. 98, 21,66721,712 .

Fialko, Y., M. Simons, and D. Agnew (2001). The complete (3-D) surface displacement field in the epicentral area of the $1999 M_{\mathrm{w}} 7.1$ Hector Mine earthquake, California, from space geodetic observations, Geophys. Res. Lett. 28, no. 16, 3063-3066.

Gilbert, L. E., C. H. Scholz, and J. Beavan (1999). Strain localization along the San Andreas fault: consequences for loading mechanisms, J. Geophys. Res. 99, no. B12, 23,975-23,984.

Hauksson, E., L. M. Jones, and K. Hutton (2002). The $1999 M_{\mathrm{w}} 7.1$ Hector Mine, California, earthquake sequence: complex conjugate strike-slip faulting, Bull. Seism. Soc. Am. 92, 1154-1170 (this issue).

Herring, T. (1999). Documentation of the GLOBK Software version 5.1, Massachusetts Institute of Technology, Cambridge, Massachusetts.

Hudnut, K., and M. Clark (1989). New slip along parts of the 1968 Coyote Creek fault rupture, California, Bull. Seism. Soc. Am. 79, no. 2, 451465.

Hurst, K., D. Argus, A. Donnellan, M. Heflin, D. Jefferson, G. Lyzenga, J. Parker, M. Smith, F. Webb, and J. Zumberge (2000). The coseismic geodetic signature of the 1999 Hector Mine earthquake, Geophys. Res. Lett. 27, 2733-2736.

Ji, Chen, D. J. Wald, and D. V. Helmberger (2002). Source description of the 1999 Hector Mine, California earthquake. I. Wavelet domain inversion theory and resolution analysis, Bull. Seism. Soc. Am. 92, 1192-1207 (this issue).

Ji, Chen, D. J. Wald, and D. V. Helmberger (2002). Source description of the 1999 Hector Mine, California earthquake. II. Complexity of slip history, Bull. Seism. Soc. Am. 92, 1208-1226 (this issue).

Johnson, H. O., D. C. Agnew, F. K. Wyatt, Present-day crustal deformation in southern California, J. Geophys. Res. 99, no. B12, 23,951-23,974.

Kaverina, A., D. Dreger, and E. Price (2002). The combined inversion of seismic and geodetic data for the source process of the 16 October $1999 M_{\mathrm{w}}$ 7.1 Hector Mine, California, earthquake, Bull. Seism. Soc. Am. 92, 1266-1280 (this issue).

Kenner, S. J., and P. Segall (2000). Postseismic deformation following the 1906 San Francisco earthquake, J. Geophys. Res. 105, 13,195-13,209.

King, R. W., and Y. Bock (1999). Documentation of the GAMIT GPS analysis software, version 9.8, Massachusetts Institute of Technology, Cambridge, Massachusetts.

Owen, S., G. Anderson, D. C. Agnew, H. Johnson, K. Hurst, R. Reilinger, Z.-K. Shen, J. Svarc, and T. Baker (2002). Early postseismic deformation from the $M_{\mathrm{w}} 7.1$ Hector Mine earthquake as measured by survey-mode GPS, Bull. Seism. Soc. Am. 92, 1423-1432 (this issue).

Peltzer, G., P. Rosen, F. Rogez, and K. Hudnut (1996). Postseismic rebound in fault step-overs caused by pore fluid flow, Science 273, 1202-1204.

Peltzer, G., P. Rosen, F. Rogez, and K. Hudnut (1998). Postseismic deformation along the Landers 1992 earthquake surface rupture, J. Geophys. Res. 103, no. B12, 30,131-30,145.

Pollitz, F. F., G. Peltzer, and R. Bürgmann (2000). Mobility of continental mantle: evidence from postseismic geodetic observations following the 1992 Landers earthquake, J. Geophys. Res. B, Solid Earth and Planets, 105, no. 4, 8035-8054.

Pollitz, F., C. Wicks, and W. Thatcher (2001). Mantle flow beneath a continental strike-slip fault: postseismic deformation after the $1999 \mathrm{Hec}$ tor Mine earthquake, Science 293, 1814-1818.

Rymer, M. J. (2000). Triggered surface slips in the Coachella Valley area associated with the 1992 Joshua Tree and Landers, California, earthquakes, Bull. Seism. Soc. Am. 90, no. 4, 832-848.

Rymer, M. J., J. Boatwright, L. C. Seekins, J. D. Yule, and J. Liu (2002). Triggered surface slips in the Salton Trough associated with the 1999 Hector Mine, California, earthquake, Bull. Seism. Soc. Am. 92, 13001317 (this issue).

Sandwell, D., L. Sichoix, D. Agnew, Y. Bock, and J.-B. Minster (2000). Near real-time radar interferometry of the $M_{\mathrm{w}} 7.1$ Hector Mine earthquake, Geophys. Res. Lett., 27, 3101-3104.

Sauber, J., W. Thatcher, S. C. Solomon, and M. Lisowski (1994). Geodetic 
slip rate for the eastern California shear zone and the recurrence time of Mojave Desert earthquakes, Nature 367, 264-266.

Savage, J. C., and J. L. Svarc (1997). Postseismic deformation associated with the $M_{\mathrm{w}}=7.31992$ Landers earthquake, southern California, J. Geophys. Res. 102, 7565-7577.

Savage, J. C., M. Lisowski, and M. Murray (1993). Deformation from 1973 through 1991 in the epicentral area of the 1992 Landers, California, earthquake $\left(M_{\mathrm{s}}=7.5\right)$, J. Geophys. Res., B, Solid Earth and Planets, 98, no. 11, 19,951-19,958.

Savage, J. C., M. Lisowski, and W. H. Prescott (1990). An apparent shear zone trending north-northwest across the Mojave Desert into Owens Valley, eastern California, Geophys. Res. Lett. 17, no. 12, 2113-2116.

Scientists of the U.S. Geological Survey, Southern California Earthquake Center, and California Division of Mines and Geology (2000). Preliminary report on the 16 October $1999 M 7.1$ Hector Mine earthquake, Seism. Res. Lett. 71, 11-23.

Shen, Z.-K., D. Jackson, Y. Feng, M. Cline, M. Kim, P. Feng, and Y. Bock (1994). Postseismic deformation following the Landers earthquake, California, 28 June, 1992, Bull. Seism. Soc. Am. 84, 780-791.

Sieh, K., L. Jones, E. Hauksson, K. Hudnut, D. Eberhart-Phillips, T. Heaton, S. Hough, K. Hutton, H. Kanamori, A. Lilje, S. Lindvall, S. F. McGill, J. Mori, C. Rubin, J. A. Spotila, J. Stock, H. K. Thio, J. Treiman, B. Wernicke, and J. Zachariasen (1993). Near-field investigations of the Landers earthquake sequence, April to July 1992, Science 260, 171-176.
Sillard, P., Z. Altamimi, and C. Boucher (1998). The ITRF96 realization and its associated velocity field, Geophys. Res. Lett. 17, 3223-3226.

Thatcher, W. (1983). Non-linear strain buildup and the earthquake cycle on the San Andreas fault, J. Geophys. Res. 88, 5893-5902.

Treiman, J. A., K. J. Kendrick, W. A. Bryant, T. K. Rockwell, and S. F. McGill (2002). Primary surface rupture associated with the $M_{\mathrm{w}} 7.1$ 16 October 1999 Hector Mine earthquake, San Bernardino County, California, Bull. Seism. Soc. Am. 92, 1171-1191 (this issue).

Wyatt, F. K., D. C. Agnew, and M. Gladwin (1994). Continuous measurements of crustal deformation for the 1992 Landers earthquake sequence, Bull. Seism. Soc. Am. 84, no. 3, 768-779.

U.S. Geological Survey

525 S. Wilson Ave.

Pasadena, California 91106

hudnut@usgs.gov

(K.W.H., N.E.K., J.E.G., K.F.S., J.A.B., A.A, S.v.W., R.M.)

Scripps Institute of Oceanography

Institute of Geophysics and Planetary Physics

University of California, San Diego

La Jolla, California 92093-0225

(S.D., F.W.)

Manuscript received 22 October 2000. 